\title{
El método en Cornelio a Lapide
}

\author{
José Antonio García Benjumea \\ Centro de Estudios Teológicos de Sevilla
}

\begin{abstract}
Resumen: Este artículo tiene un doble objetivo sobre el método utilizado por Cornelio a Lapide. En primer lugar, ver cómo ha realizado su método. Él lo definió del siguiente modo: dar solidez, brevedad, método y claridad máxima al sentido auténtico y literal de sus comentarios al dato bíblico. Nos proponemos descubrir y mostrar no sólo el método reflejo de Cornelio a Lapide, sino además ver si el método se atiene a su propio objetivo, o bien si él en el desarrollo de su propia exégesis ha modificado o introducido otros criterios que no han sido expresados en el objetivo. No solo valoramos los criterios sino también la forma de ejecutarlos. En segundo lugar, ver qué valor toma dentro del método toda la reflexión teológica. Nos preguntaremos por el método teológico que emerge de sus comentarios.
\end{abstract}

\begin{abstract}
This paper has a double objective regarding the method employed by Cornelio to Lapide. Firstly, his method, defined by himself as to give solid, short and maximum clarity to the literacy of his comments about the Bible. We pretend not only to show the method, but also to assess its fulfillment with the objective, in order to see if other criteria have been modified or introduced. We do not only assess criteria, but also the way they are performed. Secondly, we analyze the value of the theological reflection within the method. We wonder about the theological method emerging from his comments.
\end{abstract}

\section{INTRODUCCIÓN}

¿Por qué este título, el método? ¿Por qué no denominarlo método exegético, cuando nuestro autor ha sido reconocido como uno de los más grandes exegetas del comienzo del S. XVII?

Primero, aunque a primera vista, como veremos más adelante, el objetivo de nuestro autor es transmitir de forma plena el sentido genuino y literal de las cartas de San Pablo, por tanto la materia en cuestión de sus comentarios es la exégesis; sin embargo la forma de realizarlo es bajo el prisma de un teólogo que busca la verdad que encierra las Sagradas Escrituras, la búsqueda del dato de la 
fe. Su método, según nuestro criterio, podríamos definirlo como exegético-teológico (método positivo), dos elementos que queremos resaltar en este artículo.

Segundo, nuestra tesis doctoral ("La filiación adoptiva en Cornelio a Lapide: doctrina y método”, Roma 2006, PUG) es dogmática y no historia de la exégesis. Nosotros hemos elegido a Cornelio a Lapide y sus comentarios a San Pablo porque queremos ver el tema dogmático de la filiación adoptiva desde el ángulo de la ciencia bíblica para aterrizar en la ciencia teológica. Nos hacemos las siguientes preguntas en voz alta: ¿No corresponde a la ciencia bíblica de aquella época, los grandes significados y aportaciones de cara a los principios de la Escritura de los reformadores? ¿Se podría pensar, que a lo mejor, los exegetas hubiesen expuestos en sus comentarios ideas que apenas tuvieron eco en los famosos teólogos de la época en sus controvertidas discusiones teológicas?

Como bien sabemos, en la historia de la Teología a veces se pone el acento en unos aspectos más que en otros; o bien por razón de una claridad expositiva, o bien porque el momento teológico así lo requiere. Un ejemplo claro lo tenemos en el Concilio de Trento donde la reflexión y el pronunciamiento dogmático sobre la justificación es una respuesta a la doctrina de los protestantes, y generará posteriormente diferentes discusiones y controversias sobre el tema de la gracia a nivel interno de la Iglesia. Mientras que en el Concilio Vaticano II, este tema pasa desapercibido, porque su preocupación es otra muy diferente. ¿No puede ser que Cornelio a Lapide pusiera un acento en otras preguntas y que en aquella época cayeran en el olvido?

Tercero, no podemos comprender y analizar la exégesis del S. XVII como entendemos la exégesis bíblica actual. Porque la exégesis postridentina asume en su desarrollo a la exégesis de los Santos Padres y del Medioevo, donde toda la erudición teológica se concentraba en la exégesis, que con sus cuatro sentidos de la Escritura daba pie a las más ingeniosas combinaciones, lo mismo que a las más amplias especulaciones teológicas. En la medida que ha ido desarrollándose el método exegético, también ha incidido en el desarrollo posterior del método en la Teología ${ }^{1}$.

Después de aclarar el título, de ésta disertación, que nos concierne vamos a introducirnos en el método de Cornelio a Lapide para:

En primer lugar, para ver la forma como ha realizado su método. Él lo definió del siguiente modo: dar a su obra solidez, brevedad, método y claridad máxima al sentido auténtico y literal de sus comentarios al dato bíblico.Y todo ello desde el estudio crítico del texto en griego, hebreo y siríaco, y además desde los Padres y los Doctores de la Iglesia. Dejando en las manos de los lectores el juicio de si realmente ha conseguido el objetivo que se proponía en su obra. Ahora nos concierne a nosotros descubrir y mostrar no sólo el método reflejo de Cornelio

Cf. LuBAC H. DE, Exégèse Mèdièvale. Les quatre sens de l'écriture. Introducción. T. I. 1. Aubier 1959. 23-39. 
a Lapide, sino además ver si el método practicado por el autor se atiene a su propio objetivo, o bien si él en el desarrollo de su propia exégesis ha modificado o introducido otros criterios que no han sido expresados en el objetivo. Entonces no sólo tendremos que valorar los criterios sino también la forma de ejecutarlos.

En segundo lugar, para ver qué valor toma dentro del método toda la reflexión teológica. Que es nuestro principal objetivo, descubrir el método teológico que emerge de sus cometarios.

\section{CONTEXTO HISTÓRICO-TEOLÓGICO DE LA EXÉGESIS CATÓLICA S. XVI-XVII}

Antes de profundizar en el método exegético de nuestro autor es imprescindible realizar una leve mirada al periodo histórico-cultural-religioso donde Cornelio a Lapide se desenvuelve, para tener una mayor comprensión de su obra exegética.

Los eventos particulares que anteceden a la obra de Cornelio a Lapide y que crearon perspectivas nuevas en el ámbito del pensamiento exegético y de la hermenéutica bíblica fueron: el Humanismo², la Reforma protestante ${ }^{3}$, y la Reforma Católica ${ }^{4}$-promovida primero por el XVIII Concilio ecuménico Lateranense V (1512-1517) y más tarde, de forma más contundente por el Concilio de Trento (XIX ecuménico: 13 de Diciembre de 1545 -4 de Diciembre de 1563)elementos que incidirán en sí mismo en la forma de leer e interpretar el texto bíblico.

Las causas que motivaron el renacer de los estudios de la Biblia -además del acentuado movimiento humanístico que imprimió gran parte de la cultura europea del S. XV y XVI- en ésta época fueron dos: la primera, la controversia

2 Cf. TÁBet, M., Le trattazioni teologiche sulla Bibbia. Un approccio alla storia dell'esegesi. San Paolo, Milano 2003, 165-172: «El significado de la palabra "Humanismo" ha motivado múltiples discusiones en el campo de los estudios históricos. Se habla, por ejemplo, de "Humanismo" en sentido general para caracterizar cada orientación que retoma el sentido y los valores afirmados en la cultura humanística. Aquí hemos usado el término en su significado quizás más común, al referirse a aquel periodo que sigue al Medioevo y es caracterizado por un conocimiento floreciente de los estudios históricos y de las lenguas clásicas, consideradas como instrumento de elevación espiritual del hombre. Dentro de este concepto existe una acepción más limitada, que aquella del "humanismo filológico", expresión que indica la actividad que vuelve a recuperar, el estudio y las publicaciones de los textos clásicos como medio para llegar a una nueva forma de civilización (cf. SPITz, L. W, Humanismus / Humanismusforschung, TRE 15 [1986] 639-661».

3 Inicio que se puede remontar al 31 de Octubre de 1517, día en que Lutero (1483-1546) publicó las 95 tesis en Wittenberg. Seguidamente el 15 de Junio de 1520, León X condena con la bula Exsurge Domini algunos errores de Lutero (cf. DH 1451-1492), y el 3 de Enero de 1521 es formalizada la excomunión mediante la publicación de la bula Decet Romanum Pontificem.

4 El Concilio LateranenseV, convocado por el Papa Julio II en el 1512 a instancia de Tomás de Vio general de los dominicos, tenía como principal intento encauzar la Reforma de la Iglesia. Será el Concilio de Trento quien lo lleve a término. En el 1536 Pablo III concierta con el Emperador Carlos V el Concilio, que se desarrollará en diversas secciones desde 1545 hasta el 1564, con la confirmación de parte de Pio IV de todos los decretos, dándoles valor de ley (cf. DH 1500-1835). 
con la teología protestante, que con su revisión de carácter hermenéutico-bíblico tiende a poner en discusión la estructura y la doctrina tradicional de la Iglesia, y mueve en cierto modo a la teología católica a emprender el estudio del texto de la Biblia al nivel histórico-literario que ya se estaba desarrollando la investigación protestante. La segunda, el Concilio de Trento, verdadero vértice entre la edad medieval y la moderna, que recoge las nuevas instancias que se trazó en el decreto del 8 de Abril de 1546 (DH 1501-1508) como marco dentro de la cual la exégesis católica podía considerarse como tal en la comprensión de la Biblia, en cuánto conforme a la naturaleza inspirada del texto bíblico. Este decreto de Trento queriendo salvaguardar la fe católica de las nuevas instancias nacientes, define el canon bíblico de los libros Sagrados y establece la Vulgata, como versión aprobada por su uso a lo largo de los siglos en la misma Iglesia, para que sea tenida por auténtica en las lecciones públicas, disputaciones, predicaciones y explicaciones teológicas ${ }^{5}$.

Los siglos XVI y XVII -en particular los años que van desde el 1563 al 1663son reconocidos como el periodo de oro de la exégesis católica. En este periodo de tiempo el movimiento exegético de los jesuitas debe ser tenido en cuenta por su gran esfuerzo teológico proporcionado por ellos al alba del Concilio de Trento y que da sus frutos a principios del S. XVII -como es el caso de nuestro autor Cornelio a Lapide-contribuyendo a la reconstrucción espiritual y dogmática de la época ${ }^{6}$.

Cuando Cornelio a Lapide se propone como objetivo de su obra el sentido original y literal, parece más bien que él quería ante todo desarmar las críticas que los protestantes dirigían a la exégesis católica denominándola de demasiado alegórica. Pero dio además respuesta a otras preocupaciones.

La polémica con los protestantes no está en primer plano; pero sin embargo, en todas partes de su obra subyace implícita o explícitamente. Cuando los comentarios de Cornelio a Lapide se originaron ya había transcurrido tiempo de las primeras y alborotadas discusiones. Sobre unos cien años habían pasado ya de aquellas controversias y la Iglesia había respondido, aún tarde, con el Concilio de Trento, el 13 de Enero de 1547 se publica el decreto sobre la Justificación (DH 1520-1583).

Cornelio a Lapide no sólo va a refutar a los protestantes, sino que además quiere exponer una doctrina clara frente a la confusión que existía en el pueblo llano ante las nuevas doctrinas. Nuestro ofrece su obra al servicio de la Iglesia, como fundamento sólido a la doctrina expuesta en el Concilio de Trento. Finalmente proporciona con su obra un material importantísimo a los predicadores y a los defensores de la doctrina católica ${ }^{7}$.

Cf. TÁBet, M., Le trattazioni teologiche sulla Bibbia, 172-177.

Cf. Bedovelle, G.- Roussel, B., Le temps des Reformes et la Biblie, 361-368.

Cf. BARONI, V., La Contre-Réforme devant la Bible. L'exégèse des Jèsuites. Slatkine Reprints, Genève 1986, 280-284. 


\section{CORNELIO A LAPIDE COMO EXEGETA}

Al hablar de Cornelio a Lapide no estamos hablando de cualquier exegeta bíblico sino que ponemos sobre la mesa para comentar y analizar a un gran comentarista de la Biblia, estamos delante de unos comentarios que representan el esfuerzo más completo y mejor conseguido de la Contra-Reforma en el dominio de los estudios bíblicos ${ }^{8}$.

Nuestro autor comenzó siendo profesor de Escritura en la universidad de Lovaina y publicó sus lecciones a la Sagrada Escritura gracias al compromiso y las peticiones realizadas por el Arzobispo de Malines y sus superiores jesuitas. Comenzó su labor exegética por los comentarios sobre las cartas de San Pablo (1614). A continuación A Lapide fue llamado por el Papa al Colegio Romano, donde enseñó a partir del 1616.Y entre los años que van desde 1614 al 1645 aparecieron sus comentarios sobre todos los libros de la Biblia, excepto Salmos y Job?.

En el Prolegómeno de los comentarios de Cornelio a Lapide a las epístolas de San Pablo nos encontramos con una carta dedicatoria -dirigida al Arzobispo de Malines, el Ilmo y Rvdo. Sr. Matías Hovio- donde el propio autor nos deja un gran tesoro de información al describir personalmente los criterios que va a utilizar para realizar su propia exégesis ${ }^{10}$.

En esta carta, Cornelio a Lapide, nos relata que se va a fijar en cuatro elementos esenciales a la hora de componer sus comentarios: Pablo ${ }^{11}$.

Primero, la solidez, para poder explicar el auténtico pensamiento de San

Segundo, la brevedad, de este criterio nos dice Cornelio que consultó tantos comentarios de otros que hizo casi un florilegio, aunque analizando todo, abandonó la paja para quedarse con el grano. Va a citar a los Santos Padres literalmente, en cuanto la brevedad se lo puede permitir y quiere transmitir sus ideas con la misma elección y brevedad ${ }^{12}$.

8 Cf. Bedovelle, G.- Roussel, B., Le temps des Reformes et la Biblie. Ed. Beauchesne, Paris 1989, 367-368.

9 Cf. BARONI, V, L'exégèse des Jèsuites, 280.

10 Cf. A lapide, C., Epistola dedicatoria. In Epistolas divi Pauli. T. 18, Ludovicum Vivés, Parissis 1866, $5-13$.

11 Cf. A LAPIDE, C., Epistola dedicatoria, 10: «Porro hisce commentariis conscribendis et limandis multis annis asiduo et ingenti labore incubui, studuique quatuor rebus quam maxime: primo, soliditati, ut genuinam Pauli mentem explicarem».

12 Cf. A lapide, C., Epistola dedicatoria, 10-11: «secundo, brevitati, in studio enim sacrae Scripturae verissimum est illud: "Ars longa, vita brevis"; ea de causa ex tot et tam vastis aliorum commentariis quasi mellilegium feci, et relictis furfuribus pollinem dedi: mea vero pari delectu et brevitate tradidi. Citavi Patres ad verbum, quantum brevitas tulit; sed ob eam subinde illos in verbis luxuriantes restrinxi, atque sententias illorum illustriores tantum citavi, easque etiamsi disparatas, mediis omissis, conjunxi, verbo uno, aut verbi casu ad congruam syntaxin adaptato, et commutato. Illorum enim medullam et energiam paucis tradere intendi, ideoque nonnunquam, sed rarius, plura eorum verba satis involuta uno alterove meo clariore commutavi, ut prolixitatem vitarem: sed ita, ut fideliter sensa eorum semper expresserim». 
Tercero, el método, Cornelio lo describe de la siguiente forma: Después de realizar una breve resumen de todo el capítulo entra en la materia misma del texto.Y a continuación aporta de forma ordenada las interpretaciones (expositiones) más claras de los Padres y los Doctores; ya sea para que el comentario sea más pleno y perfecto, ya sea para que así aparezca la riqueza de las Sagradas Escrituras, ya sea para que con esta variedad en las cátedras, dado que la materia es mucha en este campo, se aporta a sus comentarios algo de ornamentación como también de provecho para los propios lectores ${ }^{13}$.

Cuarto, la claridad, nos dice Cornelio que es sabio y erudito lo que es claro y no lo que es oscuro: «sapiens et eruditum est quod clarum est, non quod obscurum» ${ }^{14}$.

El objetivo manifiesto que quiere emplear Cornelio a Lapide en su obra es dar de forma sólida, breve, metódica, y claridad máxima al sentido genuino y literal de las cartas (con ello asume la exégesis de los Padres), así como finalmente del resto de las Sagradas Escrituras.Y para conseguirlo quiere hacerlo desde el texto griego, hebreo y siríaco, y además desde los Padres y desde los Doctores; y con estos instrumentos Cornelio nos ofrece e ilustra el sentido auténtico del dato bíblico ${ }^{15}$.

Con el primer elemento (la solidez), Cornelio a Lapide, busca el sentido literal y original de los textos. Que para él va a ser el principio fundamental del método, de forma que reluzca el auténtico pensamiento de San Pablo. Él va a insistir en el sentido histórico, aunque esto no le va a impedir también recurrir a las cuatros interpretaciones de la escolástica ${ }^{16}$ (como veremos más adelante).

13 Cf. A LAPIDE, C., Epistola dedicatoria, 11: «Tertio, methodo, de qua mox dicam».

Añade: «Methodus mea haec est: post brevem synopsin totius capitis rem aggredior, atque illustriores Patrum et Doctorum expositiones ordine quamque suo affero: tum ut plenus et perfectus sit commentarius; tum ut S. Scripturae foecunditas appareat; tum quia haec varietas in cathedris et pulpitis, cum multa materia multum affert tam ornamenti quam emolumenti. Sensum vero illum, qui maxime genuinus videtur, expresse designo, eumque aliis praefero et illustro».

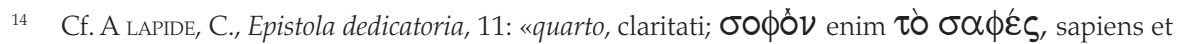
eruditum est quod clarum est, non quod obscurum. Ut quid enim lingua et sermo nobis datus est, nisi ut clare sensa mentis tum nostrae, tum alienae efferat et explicet? Ut quid diffíciles et obscuros auctores explicamus, si nostra obscuritate, licet eleganti, tam nos nostraque dicta et scripta, instar sepiarum, quam ipsos auctores magis implicamus et involvimus?».

15 Cf. A LAPIDE, C., Epistola dedicatoria, 11: «Scopus itaque meus fuit, solide, breviter, methodice et clare tradere sensum maxime genuinum et litteralem harum epistolarum, uti et reliquae deinceps S. Scripturae: ideoque ex textu Graeco, Hebraeo et Syro, atque ex Patribus et Doctoribus ea profero, quam sensum hunc genuinum vel demonstrant, vel illustrant».

16 Cf. Schmaus, M., Teología Dogmática. I. La Trinidad de Dios. Ed. Rialp, S. A. Madrid 1960, 113: «La Teología católica desde tiempos muy antiguos distingue en la Escritura varios sentidos: verbal o literal y espiritual o típico. Este último sentido se subdivide en otros tres: sentido alegórico, sentido moral y sentido analógico». También se puede consultar: Simonetri, M., Lettera e/o allegoria. Un contributo alla storia dell'esegesi patristica. Studia Ephemeridis «Augustinianum» 23 (1985). 
Con el segundo elemento (la brevedad) hace referencia al uso de los Padres $\mathrm{y}$ de los Doctores modernos ${ }^{17}$. El autor convenientemente ha colocado en su obra abundantes materiales de ellos, cuidadosamente elegidos, para descubrir el verdadero sentido del texto. Ante la abundancia del material que existe Cornelio quiere y desea ser breve en su exposición.

Con el tercer elemento (el método) quiere ser metódico en toda su obra, imprimiendo una idea directriz: el sentido literal. Y así conseguir una perfecta unidad en su método personal.

Y con el cuarto elemento (la claridad), nuestro autor no quiere perderse en cavilaciones metafísicas y especulaciones abstractas; sino al contrario, quiere abandonarse a los estudios de las fuentes y al examen de autores anteriores a él.

En definitiva, Cornelio a Lapide ve como el sentido literal y original es el principio fundamental de su método. Para la forma de conseguirlo él se propone ser sólido, breve, metódico y claro ${ }^{18}$.

\section{CORNELIO A LAPIDE Y EL MÉTODO EXEGÉTICO}

En este apartado vamos a describir el método exegético de Cornelio a Lapide en las cartas de San Pablo -incidiendo en aquellas que han sido objeto de nuestro trabajo teológico- según el propio autor.

La idea principal u objeto de su método a la hora de realizar su obra literaria -como ya hemos dicho anteriormente- ha sido el sentido literal de los textos bíblicos; aunque siendo diferentes los comentarios entre ellos (como diferentes son los libros del Antiguo y Nuevo Testamento, y como son diferentes los libros en cada uno de ellos) les quiso dar unidad en su método personal en todos sus volúmenes. Tendremos que preguntarnos al final de este trabajo si ha sido así o no.

Los instrumentos que permiten responder a este objeto de sus comentarios, según Cornelio a Lapide, y que ilustran el sentido genuino de San Pablo son desde el texto griego, hebreo y siríaco; desde los Padres y desde los Doctores de la Iglesia, que desarrollaremos de forma más pausada en un segundo momento de este apartado. Ahora nos centramos en describir el estilo, forma y estructura de su trabajo exegético.

El estilo que Cornelio a Lapide quiere utilizar es el estilo metódico y didáctico, porque considera que es el más usado por las escuelas para la disciplina y es

17 Cf. Latourelle, R., Teología, ciencia de la Salvación. Ed. Sígueme, Salamanca 1968, 98-99: «Se entiende por Padres de la Iglesia aquellos que son testigos de la Tradición. La noción de Padre de la Iglesia está caracterizada por cuatro rasgos: antigüedad, ortodoxia de su enseñanza, aprobación expresa o implícita de la Iglesia, santidad. Se considera a la era patrística como cerrada, en occidente, con san Gregorio (604) y san Isidoro (636) y en oriente, con san Juan Damasceno (749). El término Doctor de la Iglesia es más restringido que el de Padre. Cuando se hace expresa la estima general que la Iglesia tiene para un Padre, éste queda elevado al rango de Doctor. El Doctor de la Iglesia se distingue además por el papel eminente que ha desarrollado en la vida doctrinal de la Iglesia».

18 Cf. Galdos, R. S. I., De scripturisticis meritis Patris Cornelii a Lapide, VD 17 (1937) 39-44. 88-96. 
el más apto para el conocimiento (con ello, asume el método escolástico). Él va a incidir sobre todo en el comentario en distinguir entre los puntos esenciales y las partes por medio de notas, cuestiones, números, etc. Como podemos observar en la siguiente exposición ${ }^{19}$ :

v.13. Si VIVÍS SEGÚN LA CARNE, MORIRÉIS; PERO SI EN EL (POR MEDIO DEL) ESPÍRITU DAIS MUERTE A LAS OBRAS DE LA CARNE, VIVIRÉIS.

El Apóstol muestra aquí a los cristianos con seis argumentos qué es vivir según el espíritu y no la carne; para ello, propone los seis versículos siguientes. El primero es este versículo: porque si viven según la carne, morirán con la muerte eterna del gehenna; mientras que, si viven según el espíritu, vivirán la vida bienaventurada y eterna.

El segundo es el v. 14, porque, si viven según el espíritu, no sólo serán llamados, sino que serán hijos de Dios.

El tercero es el v. 15, porque han recibido el espíritu de adopción para que vivan propiamente según el espíritu.

El cuarto es le v. 17, porque, si hacen esto, serán herederos de Dios.

El quinto es el v. 18, porque los padecimientos, que hemos de sostener por la vida espiritual, no son comparables con la gloria futura, que se revelará en nosotros.

El sexto indica el v. 20, porque dicho de otro modo, si no sirven al espíritu, sino a la carne y a las criaturas, sirven a la vanidad: porque toda carne y toda criatura están sujetas a la vanidad y a la corrupción ${ }^{20}$.

El estilo utilizado por nuestro autor -el escolástico- le impide, de por sí, adornar la materia, existiendo una ausencia de elegancia en sus palabras. Él mismo se define como un teólogo que busca la verdad en sus comentarios y la utilidad, haciendo resaltar la doctrina de San Pablo, porque su deseo es enseñar las cosas discutidas o las opiniones que no están claras a través de los Padres y los Doctores de la Iglesia, colocando siempre por orden sus exposiciones o interpretaciones, posteriormente señala aquel sentido más correcto para el texto y lo expone, como podemos comprobar:

Dirás: «Este testimonio proviene del Espíritu Santo; por lo tanto, es absolutamente cierto».

Respondo: es cierto, sin duda, en sí mismo; pero no es cierto, ya que nosotros no estamos absolutamente seguros de que aquel testimonio provenga del Espíritu Santo y no, del diablo. [...].

Preguntarás: «Pero, ¿Qué es este testimonio?» Responde primero Orígenes que éste es cumplir la ley de Dios no desde el temor, sino desde el amor, de lo cual nosotros tenemos experiencia.

19 Cf. A Lapide, C., Carta dedicatoria, 11: «Quare stylo utor didactico et methodico, per notationes, quaestiones, numeros, membra et puncta inciso et distincto, qui in scholis usitatus ad disciplinam et memoriam aptissimus est: hic enim ornari res ipsa vetat, contenta doceri».

20 Cf. ComRomVIII, 133. 
Segundo, Ambrosio y Anselmo responden que es la imitación de Dios y de Cristo; pues, por medio de ella, somos hechos semejantes a Dios y, en consecuencia, hijos de Dios.

Tercero, Teodoreto responde que este testimonio es la sagrada doctrina, la cual enseña que los que obedecen a Dios, como un padre, y le invocan son hijos de Dios.

Cuarto, Sedulio responde que es el Espíritu Santo, que nos ha sido dado. Éste, en efecto, da testimonio de que somos hijos de Dios.

Quinto, San Juan Crisóstomo y Toledo responden, de forma óptima, que este testimonio es el clamor, del cual ha hablado el Apóstol en el versículo precedente. Pues, mientras clamamos con afecto filial (por medio del Espíritu Santo): "Abba, Padre", $^{\prime}$ nuestro mismo clamor (y el Espíritu Santo, autor del clamor, junto a nosotros) testifica, como entiende el griego, que somos hijos de Dios, sobre todo, si accede al espíritu, $[\ldots]^{21}$.

Muchas veces el mismo Cornelio a Lapide no rebate las interpretaciones expuestas, bien por no alargarse en el comentario, bien por respeto al autor, bien porque muchas son probables, o bien porque la proposición y confirmación de la sentencia verdadera y genuina es en sí misma la refutación de las afirmaciones contrarias ${ }^{22}$ :

PARA QUe ReCibiÉRAmOS la ADOPCIÓN.- Nota ${ }^{23}$ la conjunción ut, como si dijese, el Hijo de Dios se hizo de mujer hijo del hombre, para hacer y adoptar los hijos del hombre como hijos de Dios. Por tanto dice San Bernardo «Dios se ha hecho hombre para que el hombre se haga Dios».

[Nota] Fíjate en segundo lugar: esta adopción se hace por medio de la gracia, en la cual nosotros obtenemos no solo el derecho a la herencia de Dios Padre, sino también en la participación de la naturaleza divina, y el mismo Espíritu Santo y la filiación de Dios, como se dijo en Rom VIII, 15.

[Nota] Fíjate en tercer lugar: todos los justos, antes incluso de Cristo han sido hijos adoptivos de Dios; pero sin embargo el Apóstol los llama antes de Cristo siervos ${ }^{24}$.

Cornelio a Lapide, como hemos visto, utiliza de forma didáctica la conexión y la fuerza de los razonamientos de San Pablo allí donde son oscuros.

Ahora, en este momento de nuestro trabajo, es necesario hacer una exposición de cómo todos estos elementos y los instrumentos que ilustran y dan luz al sentido genuino del texto bíblico se han desarrollado a lo largo de nuestro

21 Cf. ComRomVIII, 135.

22 Cf. A lapide, C., Carta dedicatoria, 11: «Quamobrem florida et parerga non sector, nec elegantiam ambio; Theologum enim ago, non oratorem; veritatem vestigo, utilitatem quaero, non umbras et pompam; insisto rebus, non verbis: praesertim cum Apostolus ipse, quem interpretor, profiteatur se imperitum sermone, sed non scientia, 1 Cor II. [...]. Qui enim verborum elegantiae studet et incumbit, necesse est ut tantumdem rerum ipsarum studio et profunditati demat et detrahat».

23 Con la palabra «Nota» Cornelio a Lapide quiere llamarnos la atención, es como si nos dijese «Fíjate» en lo que viene a continuación.

24 Cf. Com GallV, 551. 
trabajo descriptivo de la doctrina de Cornelio a Lapide sobre la filiación adoptiva en los comentarios - que a lo largo de la tesis, hasta ahora, hemos hecho referencia- a las cartas paulinas y otros paralelos.

Antes de comenzar queremos aclarar que para Cornelio la palabra Padre, designa desde los Santos Padres hasta la Edad Media y el Concilio de Trento. Con la mención de las tres lenguas - griego, hebreo y siríaco- asume el espíritu humanista con el que quiere leer los textos en la lengua original.Y con la palabra Doctores se adapta al desarrollo de la tarda Edad Media que siempre tiene en cuenta los autores entonces modernos. La metodología adoptada por Cornelio a Lapide recoge toda una rica tradición exegética, que a través del medioevo, entronca con la antigüedad que enlaza con las aportaciones del humanismo cristiano para hacer frente a la tesis del libre examen de la Escritura propuesta por Lutero.

\subsection{A la luz de los textos originales}

A tenor de una lectura atenta de la obra de nuestro autor descubrimos a un Cornelio a Lapide que transpira y refleja un gran conocimiento de la Biblia. Que utilizó y accedió para su laborioso estudio de las Sagradas Escrituras ir a lo más inmediato y directo de las mismas fuentes ${ }^{25}$.

El texto bíblico usado como punto de partida en la obra de Cornelio a Lapide va a ser la Vulgata, como ya había aconsejado el mismo Concilio de Trento al decretar como auténtico para aquellos que fuesen a interpretar las Sagradas Escrituras en materia de fe y costumbres para la edificación de la doctrina cristiana (DH 1506-1507). La Vulgata va a ser sometida por nuestro autor a veces a la crítica textual y la confrontación con los originales en la versión griega y hebrea; y no sólo por estas lenguas sino también la versión en siríaco y por una versión anónima en arábico ${ }^{26}$, lo cual ilustramos con el siguiente ejemplo:

Авва.- En Hebreo אב ab, en caldeo y siríaco Abba, y en la término Latino y Griego Abbas, es lo mismo que Padre. Véase lo dicho en Rom VIII, $15^{27}$.

ABBA, PADRE.- ho pater (es decir, el padre) es un nominativo, al cual la versión Siríaca considera puesto aquí para reforzar al vocativo. Por eso, esta versión traduce: "abba abum", es decir," abba, padre nuestro".

En segundo lugar y propiamente, como si Pablo dijera: "Abba, que significa padre". Pues padre es caso nominativo y se añade para que explique el hebreo, o

25 Cf. A lapide, C., Prooemium in Evangelia Evangeliorum, in SS. Matthaeum et Marcum. T. 15, Parissis $1889,14$.

26 Cf. Andrés martínez, M., Historia de la Teología Española. Tomo II. Desde finales del S.XVI hasta la actualidad. Fundación Universitaria Española. Seminario Suárez. Madrid 1987, 128: «A lo largo del siglo XVII la polémica sobre temas de crítica textual remiten casi por completo. En la práctica, los exegetas no tendrán grandes reparos en llevar a cabo sus comentarios literales echando mano de los textos griegos y hebreos, cuando se hace necesario para clarificar el sentido del texto jeronimiano o profundizar en él».

27 Cf. Com GallV, 551. 
mejor el caldeo Abba. Por esto la Biblia Regia y la Romana incluyen tò ${ }^{28}$ pater en un paréntesis, del mismo modo que en Jn 1, 38 se dice: "Rabí (que significa maestro)". Pablo, pues, alude aquí al evangelio de San Marcos, el cual sabía que había sido escrito en Roma y era bien conocido por los romanos. Ya que Mc 14, 36 dice: "Abba (se sobrentiende: es decir) padre". Cristo, en efecto, no dijo, en griego ni en latín, tó pater, sino que dijo simplemente, en hebreo, o mejor dicho en sirio-caldeo, tó Abba; lo cual explica Marcos añadiendo padre. El Apóstol toma estas dos lenguas aquí (así como en Gal 4, 6), para significar -como dice San Agustín en De Spirit. et Litt., cap. XXXII, y Anselmo- que Dios es el mismo y, para él, la adopción de los judíos y de los gentiles es la misma. Pues Abba es el idioma y la palabra propia de los judíos; pater, de los griegos y los gentiles ${ }^{29}$.

El Concilio de Trento aprueba sólo como autentica de la versión de la Vulga$\mathrm{ta}^{30}$. Nos encontramos ante un tema no discutido: el texto inspirado. Se nos dice que quien nos habla es el mismo Espíritu Santo autor de la Escritura; por lo tanto no puede existir error en él. El Concilio de Trento afirma y define que los libros que constituyen e integran la Biblia católica, deben ser tenidos por sagrados y canónicos (DH 1501-1505), pero sin dar paso a la discusión; el Concilio no desciende a detalles acerca de las condiciones y razones de su carácter sagrado y canónico ni se explicita como se lleva a cabo la inspiración en el autor humano del libro sagrado, sólo se basa en la utilización por siglos de la Iglesia del texto de laVulgata ${ }^{31}$.

A Lapide admite, no obstante, que el texto sagrado no ha sido hecho por todas partes de la misma manera. Así como la Ley y los Profetas han sido dictados palabra a palabra; sin embargo, para los relatos y exhortaciones morales ha bastado sólo que el Espíritu Santo asistiera a los escritores que relataban sus recuerdos o que explican sus reflexiones para preservarlos de todo error y para sugerirles tal cosa mejor que otra. En efecto, para Cornelio a Lapide el Espíritu Santo ha sido quien ha dirigido toda la obra de la Sagrada Escritura, él es el autor de la Escritura ${ }^{32}$.

Nos encontramos aquí con un primer problema que podríamos denominarlo de unidad metodológica en el uso de los textos inspirados y los no inspirados por parte de nuestro autor. Cornelio a Lapide no justifica en su método la relación entre el uso de laVulgata y las otras versiones. Nosotros descubrimos que nuestro

28 «tò» El artículo neutro en griego sirve en el hilo argumentativo del autor para introducir un concepto en el discurso latino: la palabra "....", uso hecho por Quintiliano y recogido por los humanistas. Lo solemos encontrar también casi siempre con «Nota» (Fíjate) y a continuación un término que quiere resaltar a la vista del lector. (Cf. Lateinische Stilistik von Nägelsbach, die guechische Artikel, $21 \mathrm{~s})$.

29 Cf. ComRomVIII, 134.

30 El Concilio de Trento declaró"auténtica" en sentido jurídico la Vulgata, es decir, en todo lo que concierne la "fuerza probatoria en materia de fe y de moral", pero no excluyó el hecho de las divergencias posibles del texto original y de las antiguas versiones ... (DH 3796).

31 Cf. BAROni, V., L'exégèse des Jésuites, 280-281.

32 Cf. Pagano, S., Análisis Notionis Inspirationis S. Scripturae apud Cornelium A Lapide. Revue de l’Universitè d'Ottawa 15 (1945) 65*-85*. 
autor parte del texto de la Vulgata, que posteriormente es analizada bajo la crítica textual del texto griego (que en el fondo es la base o fundamento de su método), y posteriormente es cotejado con otras versiones del texto bíblico en otras lenguas. La solución que nosotros podemos comprender y ofrecer es que Cornelio a Lapide quiere dar luz con los textos no inspirados a los inspirados, que son los que tienen toda la autoridad para la Iglesia. Con ello, quiere mostrarnos la autenticidad de dicho texto como versión oficial de la Iglesia, porque el cotejo de los diferentes códices puede ayudar a aclarar muchos pasajes oscuros, de forma que cada uno mutuamente se atestiguan, pues la traducción de uno aclara la del otro ${ }^{33}$.

Roma va a ser de una gran ayuda para nuestro autor. Su presencia y estancia en esta ciudad le ayudará a conocer y a poder consultar las versiones del evangelio en copto, en etiópico y persa ${ }^{34}$. Estas versiones se encuentran tanto en la Biblioteca del Vaticano como en el Colegio Romano. Cornelio intentará utilizar estas versiones en el momento adecuado, ya que no tienen el reconocimiento de los textos griego y latino. Pero sin embargo le servirán en su trabajo para ilustrar las versiones griega y latina y también para confirmarlas. En esta ciudad, Cornelio a Lapide, conocerá a sacerdotes etíopes que frecuentan el Colegio Romano y además conocerá expertos en las lenguas egipcia y persa. En este conocimiento de las lenguas orientales resalta Cornelio la colaboración del P. Anastasio Kircher, de la Compañía de Jesús, experto conocedor de estas lenguas ${ }^{35}$.

Cornelio a Lapide también descubrió en la Biblioteca del Vaticano y en la Medicea la versión siríaca de la Biblia y también una versión anónima arábiga. De esta última dice el propio Cornelio que existen dos copias; una de ellas llegó a Roma desde Antioquia, por lo que se le conoce como la antioquena y la otra, procede de Egipto, conocida como la alejandrina. Ambas versiones han sido traducidas al latín por el Rvmo. Sr. Sergio Risio, marionita, arzobispo de Damasco. Para la versión latina del siríaco le fue de gran ayuda el R. P. Juan Bautista Ferairo de la Compañía de Jesús, profesor de esta lengua en el Colegio Romano ${ }^{36}$.

33 Cf. CAsciaro Ramírez, J. Mª., Exégesis bíblica, hermenéutica y teología. Ediciones Universidad de Navarra, S. A. Pamplona 1983, 262: «A partir del Renacimiento la exégesis teológica cede paso al interés por conocer a fondo los elementos filológicos, el marco histórico, geográfico e institucional en el que se insertaron los textos inspirados. El mayor conocimiento de las lenguas originales bíblicas y de las antiguas versiones estimulan a revisar y depurar el propio libro sacro, preludiando así los estudios de crítica textual, literaria e histórica. En general, la exégesis tiende a pasar del interés espiritual y teológico hacia lo histórico».

34 Aunque nuestro trabajo se centra en las cartas de San Pablo y no en los evangelios, dicha labor puede iluminarnos sobre el conocimiento adquirido por Cornelio a Lapide en estas lenguas.

35 Cf. A lapide, C., Prooemium in Evangelia, 13-15: «Romae pariter, in Bibliotheca Vaticana et in nostra collegii Romani, reperi Evangelia coptice sive aegyptiace, aethiopice et persice conscripta, illaque vetusta; [...] His ómnibus subinde utar, sed sobrie et cum grano salis; non enim habent istam auctoritatem et fidem quam obtinent Evangelia graeca et latina; illa tamen confirmant, et subinde illustrant. [...] Hi mihi Evangelia suae gentis et linguae interpretati sunt, ac praesertim R. P. Athanasius Kircher, Societatis nostrae, linguarum orientalium peritus, uti patet ex earum Lexico, quod nuper edidit».

36 Cf. A LAPIDE, C., In Isaiam argumentum, T. 11, Parisiis 1860, 100. 
Hemos de añadir como también además de usar las lenguas clásicas -dentro del espíritu humanista- utiliza e introduce en sus comentarios relatos extraídos de la antigüedad pagana, comparándolos con el texto bíblico. Así también realiza una lectura del Antiguo Testamento desde Cristo (hace una lectura del A. Testamento desde la luz del N. Testamento), como veremos en el siguiente ejemplo:

Fíjate: en griego no es «su Hijo» sino $\imath \nu \tau \hat{\omega} \eta \gamma \gamma \alpha \pi \eta \mu \varepsilon \dot{\varepsilon} \nu \omega$, in dilecto (el amado), es decir absolutamente en todos, y entre todos, sin el cual (el amado) ninguno de los demás es amado, y que es la causa por la cual todos los demás son amados. Así Jerónimo. Así Cristo en el Salmo XXVIII, 6, al cual, a lo mejor el apóstol hace alusión aquí, es llamado «dilectus quemadmodum filius unicornium» (es llamado de la misma manera que el hijo del unicornio); porque así como las crías jóvenes de los unicornios son muy amables y graciosos, así también Cristo. Segundo, porque Cristo potentísimo como el rinoceronte solamente fue concebido en el seno de la Santísima Virgen, como dije en Núm XXIII, 22; en donde también se dice de él: «su fortaleza es semejante al del rinoceronte», Pues en hebreo דאם reem significa no sólo rinoceronte, sino también monoceronte, o unicornio. Tercero, porque el cuerno del unicornio tiene dos brazos al modo de una cruz, dice Justino el Mártir, y es modesto y vigoroso; tales también la cruz de Cristo. Cuarto, el unicornio con el tacto de su cuerno purifica las aguas del veneno de las serpientes; así Cristo tocando el Jordán hizo de las aguas del bautismo purificadoras del pecado. Quinto, porque Cristo como el unicornio tiene en la cabeza, es decir, en la divinidad y en su comunión y unión con Dios, el cuerno, esto es toda su fortaleza. Sexto, así como desgajados los cedros por el trueno, aparecen brincando las crías del unicornio, lo cual significa literalmente el citado Salmo XXVIII, 6; así también alegóricamente Cristo apareció en el mundo una vez desgajados los cedros, es decir, la soberbia, la impiedad, y la idolatría, por la fuerza del trueno del evangelio; y entonces hizo patente su imagen, su belleza y gracia. Por consiguiente él es el amado del Padre, él es nuestro amado, nuestro amor, deseo, gozo, alegría, descanso, saciedad, la salud de nuestra alma, de modo que la esposa en el Cantar de los Cantares nosotros dijésemos:«Mi amado es semejante a un cervatillo, mi amado es para mí y yo soy para aquel se apaciente entre los lirios hasta que aparezca el día y se inclinen las sombras» (Cant. II, 9. 16-17) ${ }^{37}$.

Advertimos también en este texto que su declaración de principio no le impide recurrir a las cuatro sentidos o interpretaciones de la exégesis medieval, no sólo Cornelio ve el sentido literal, sino también el alegórico, el tropológico. Pero siempre en un segundo momento del comentario, el principal o base del comentario es el literal o histórico.

En la descripción de nuestro tema, la filiación adoptiva del cristiano, nos detuvimos en el capítulo tercero en el texto paulino de Gálatas 4, 6. En dicho texto veíamos como Cornelio da la primacía a la filología para poder destacar ante el lector la genuina doctrina de San Pablo. Cornelio a Lapide después de haberse

37 Cf. ComEphI, 590. 
centrado en el aspecto filológico sobre la cuestión del quoniam (ő $\tau \imath)$ sobre si tenía un sentido causal o declarativo, pasa a un segundo plano como es la exégesis, sobre una cuestión principal: ¿Qué nos enseña este versículo sobre las relaciones entre el Espíritu Santo y nuestra filiación adoptiva: o bien es sólo un testimonio, como resultado de la discusión gramatical, o bien es el Espíritu Santo quien opera nuestra adopción, como expone la teología tradicional?

Nuestro autor declaraba la conjunción quoniam en un sentido causal: «Porque sois hijos, Dios envió su Espíritu, no a que os haga hijos, sino que, ya hechos hijos, os enseñe a clamar "Padre"». Para Cornelio quoniam es la causa no de la filiación sino del clamor ${ }^{38}$.

Esta posición de Cornelio a Lapide sobre este versículo de Gál 4, 6, hace que se distancie de la teología tradicional que mantenía que el Espíritu Santo es la causa de nuestra filiación adoptiva; mientras que él solo descubre en este versículo la acción del Espíritu como testimonio de que somos hijos de Dios ${ }^{39}$.

A primera vista puede parecer que existe una contradicción entre los comentarios de Cornelio a Lapide de Rom 8, 15: «el mismo Espíritu Santo, por el cual fuimos adoptados como hijos de Dios» y Gál 4, 6: «envió su Espíritu, no para que os haga hijos sino para que nos enseñe a gritar Abba». Sin embargo, como vimos en el desarrollo del capítulo tercero ambos textos paulinos se complementan. Es cierto que existe una incertidumbre por parte de los exegetas sobre este versículo de Gál 4, 6, porque no es fácil distinguir en San Pablo si el $\pi \nu \varepsilon v \mu \alpha$ es el Espíritu Santo en persona o su efecto o don: ¿Por lo tanto, es el don o el Espíritu Santo mismo quien nos hace hijos de Dios? Según cada autor le dará un sentido u otro.

Como hemos podido comprobar que una discusión puede comenzar en el campo estrictamente filológico, para pasar posteriormente al exegético, y terminar en el campo teológico:

6. QUONIAM AUTEM ESTIS FILII, MISIT DEUS SPIRITUM FILII sUI.- Esto es, el Espíritu Santo, el cual procede del Hijo y del Padre.

Fíjate: el argumento procede del signo o efecto hasta la causa, o mejor dicho hasta alcanzar la causa, como cuando digo: "Allí hay humo, allí hay fuego"; aunque es cierto que el fuego es lo primero y es la causa del humo, sin embargo el humo se nos muestra primero a nosotros, para que nosotros deduzcamos de esto que a allí hay fuego. Así aquí es primero que Dios envía a nosotros el Espíritu Santo que nosotros somos hijos de Dios, porque por medio del Espíritu Santo nos ha hecho hijos; o dado que porque somos hijos de Dios, casi a posteriori deducimos que correctamente que Dios ya ha enviado a nosotros antes su Espíritu. Por consiguiente la voz quoniam o quia, significa no la causa en sí, sino la causa del conocimiento, o mejor dicho la necesaria consecuencia y conexión.

38 Cf. Com GalIV, 551: «Secundo et simplicius, quoniam proprie significat causam non filiationis, sed clamoris, q.d. Quia estis filii Dei, Deus misit Spiritum suum, non qui filios vos faciat, sed qui vos filios jam factos doceat clamare: "Abba, Pater" $»$.

39 Ver el capítulo tercero de la tesis. 
En segundo lugar y más simple, quoniam, significa propiamente la causa no de la filiación, sino del clamor, como si dijera, porque sois hijos de Dios, Dios envió su Espíritu, no para que os haga hijos, sino para que a vosotros, que ya sois hijos, os enseñe a gritar"Padre". Esto lo traduce Maldonado del griego de otra manera en Notis manuscr: ö $\tau$, o sea, quoniam, lo toma por quod, por consiguiente traslada, para que seáis hijos (aquí aparece el quod) enviará Dios (a vosotros) el Espíritu de su Hijo. Pero aún así muchas cosas deben cambiarse y añadirse, las cuales no se encuentran en el texto, es decir todas ellas incluidas entre paréntesis. Mejor el Nuestro, y más propio traducir $\tau$ ò ǒ $\tau$ p por quoniam ${ }^{40}$.

De nuevo debemos hacer una constatación metodológica. Cornelio a Lapide no dice qué relación existe en su método sobre la filología y los Padres. En el ejemplo expuesto anteriormente da una prioridad a la filología sobre la teología tradicional de los Padres, dando a entender una cierta ruptura entre la filología y el sentir de la teología tradicional.

\subsection{A la luz de los Padres}

Quien se acerca a conocer los comentarios de Cornelio a Lapide la primera impresión que se lleva es la gran referencia que hace a los Padres de la Iglesia, pues no hay versículo comentado que no haga referencia a ellos de una forma explícita o implícita. No sólo se conforma con citar los nombres de dichos Padres, sino además la obra de referencia sobre donde se encuentra la idea o pensamiento de cada Padre expuesta en el comentario. Con este dato podríamos deducir que Cornelio a Lapide conoce de primera mano los textos originales -lo que supone un gran esfuerzo por su parte- de los Padres tanto griegos como latinos.

Realizaremos ahora un recorrido de forma cronológica por algunos de los $\mathrm{Pa}$ dres de la Iglesia que ha utilizado Cornelio a Lapide a lo largo de sus comentarios.

En primer lugar hemos de decir que en los Padres de los dos primeros siglos -Padres apostólicos y apologéticos- no han dejado propiamente comentarios a la Sagrada Escritura, a pesar de haberla citado frecuentemente en sus instrucciones a los fieles o en sus obras con fin apologético. De entre ellos vamos a resaltar a S. Ireneo ${ }^{41}$ (140-202), final de la época apostólica, dentro de un contexto apologético, apostó por una exégesis literal y teológica. Contribuyó a la exégesis cristiana valorando la hermenéutica de la tradición viva de la Iglesia, además tenía una concepción unitaria de la Escritura y de la historia de la Salvación.

40 Cf. Com GaliV, 551.

41 Ireneo aparece citado dos veces (en los textos que hemos utilizado como base de nuestra tesis). Esencialmente con el tema de la recapitulación de todas las cosas en Cristo (cf. ComEphI, 392). Además de la referencia al germen de la teología patrística del intercambio (en palabras de S. Bernardo), porque el Hijo de Dios comparte nuestra condición humana, así también nosotros podemos compartir su condición divina siendo hijos en el Hijo (cf. ComGálIV, 551). 
El primer movimiento de la exégesis bíblica surge en Alejandría de Egipto con el nombre de Didaskaleion, y su producción teológica-exegética duró hasta el siglo V. Este movimiento comienza con Orígenes ${ }^{42}$ (185-253) que utiliza el método alegórico. De entre los miembros de esta escuela resaltamos a San Atanasio $^{43}$ (+375), Dídimo el Ciego ${ }^{44}(+380)$, San Cirilo de Alejandría ${ }^{45}(+444)$.

Una segunda escuela exegética surge en Antioquia de Siria (hacia el año 280). El método teológico seguido, se opone al alegorismo de Alejandría, es el sentido literal, entendido e interpretado a la luz de la gramática y de la historia. Gracias a este primado del sentido literal, esta escuela desarrolló la doctrina de la teoría, que dio lugar a la exégesis tipológica. Hay que resaltar a San Juan Crisóstomo ${ }^{46}(+407)$, y Teodoreto de Ciro $^{47}(+460)$. Y como representantes menores a Ecumenio y Teofilacto.

También tendremos que tener en cuenta a los Padres Capadocios, cuya posición teológica es intermedia entre la escuela de Alejandrina y la Antioquena. Los nombres más importantes son San Basilio el Grande ${ }^{48}(+379)$, San Gregorio Nazianzeno (+390) y Gregorio Niseno ${ }^{49}(+394)$. Usan la exégesis literal junto con la exégesis tropológica o moral y la alegórica. Su exégesis es sobre todo una lectura cristocentrica de la Biblia en la cual Cristo aparece como el que da sentido a la historia y como modelo de la vida del cristiano.

En los Padres Occidentales predomina el interés práctico por los problemas de orden pastoral. En el siglo III nos encontramos con Tertuliano ${ }^{50}$ (+ después del 220) que usa el sentido literal. San Hipólito Romano (+235) considerado el

42 Orígenes -aunque no es considerado Padre, por no ser garantía de ortodoxia (cf. Di BERNARDINO, A., Diccionario Patrístico y de la Antigüedad Cristiana. T. II. Ed. Sígueme, Salamanca 1998, 1643)aparece citado unas once veces. En concreto más veces en el comentario de Rom 6, 4-7, con el tema de ser injertados en Cristo.

43 San Atanasio aparece citado unas tres veces. Un ejemplo lo encontramos en el comentario a Oseas, cuando se trata el tema de la inhabitación de la Santísima Trinidad, que no se puede separar del Espíritu Santo (cf. ComOsI, 297).

44 Dídimo aparece unas dos veces. Principalmente en el comentario a Efesios, con el tema de la sigilación del Espíritu Santo en el alma justa (cf. ComEphI, 594).

45 San Cirilo aparece unas cinco veces. Mayoritariamente en el comentario de Rom 8. Destacamos su referencia «a todos los cristianos» en la comprensión de «teniendo las primicias del espíritu» (cf. ComRomVIII, 139).

46 San Juan Crisóstomo aparece unas treinta veces. Su referencia es prioritaria en todos los comentarios. Algo curioso es que Cornelio no cita sus obras, por lo que entendemos que se refiere al mismo comentario del texto bíblico. Por poner un ejemplo significativo sobre el tema del testimonio del Espíritu Santo en el clamor filial del cristiano: «Abba, Padre» (cf. ComRom VIII, 135).

${ }_{47}$ Teodoreto aparece citado unas doce veces. En Rom 8, 20 aparece junto a S. J. Crisóstomo, Teofilacto y Ecumenio (cf. ComRomVIII, 139).

48 S. Basilio aparece en nuestros comentarios unas cinco veces. Resaltamos su mención en Oseas 1, 10 y 2 Pe 1, 4, con la homilía De Spiritu Sancto, de la presencia acerca de la inhabitación del Espíritu Santo siendo Dios en los Santos (cf. ComOsI, 298).

49 Tanto S. Gregorio Nazianceno como Gregorio Niseno aparecen dos veces cada uno.

50 Tertuliano aparece unas seis veces. Sobre todo en Rom 6, 5 con el tema de la resurrección de la carne (cf. ComRomVI, 108-109). 
primer comentador de la Biblia en occidente, con clara preferencia por el método exegético alegórico.

La exégesis alegórica-alejandrina está representada por San Hilario de Potiers $^{51}$ (+367), San Gregorio de Elvira ${ }^{52}$ (+ después del 392), San Ambrosio de Milán ${ }^{53}(+397)$.

Los más importantes exegetas del S. IV y V son el Ambrosiaster (se designa a partir del S. XVI al autor desconocido del comentario a las 13 cartas de San Pablo, escrito sobre el año 380 y por mucho tiempo atribuido a San Ambrosio, de ahí el nombre de "Ambrosiaster"); San Jerónimo ${ }^{54}$ (+419) elaboró una exégesis altamente filológica, se mueve hacia el método exegético basado en el sentido literal. Entre sus obras más importantes la versión latina de la Biblia, llamada Vulgata. Y el gran San Agustín ${ }^{55}(+430)$ que se atiene a una interpretación principalmente dogmática y doctrinal. Se declina por el método exegético literal. Las reglas hermenéuticas son expuestas en su obra De doctrina christiana ${ }^{56}$.

De entre todos los Padres de la Iglesia en Cornelio a Lapide encontramos una preferencia en su obra por San Juan Crisóstomo, San Ambrosio y S. Agustín. También tenemos que incluir dentro de los Padres citados por Cornelio a Lapide a San León I (+461), San Anselmo (+1150) y San Bernardo (+ 1153), llamado a veces el último Padre de la Iglesia ${ }^{57}$.

En realidad, este gran tesoro, que se encuentra en sus comentarios nos aportan y acercan a opiniones tan diversas y explicaciones tan proliferas, como las que cuidadosamente ha elegido para que el comentario del texto bíblico exprese con la mayor claridad y brevedad -según su juicio- lo que es error o dogma de fe, doctrina cierta y probable o improbable. Lo que para nuestro autor ha significado un trabajo previo para descubrir el sentido literal, cual el más auténtico, cual el alegórico, el tropológico o el analógico. Veamos a continuación un ejemplo:

51 San Hilario aparece unas cinco veces. La referencia para Cornelio va a ser su libro De Trinitat. (cf. ComRomVIII, 138).

52 San Gregorio aparece en varios comentarios sobre todo con su obra de Moral, en concreto en Rom 8, 16.

53 San Ambrosio, de los Padres occidentales más citados por Cornelio a Lapide, junto a S. Juan Crisóstomo y San Agustín en cualquier de los comentarios de Cornelio podemos encontrarlo.

54 San Jerónimo aparece sobre unas veinte veces. Y en especial en el comentario a la carta a los Efesios 1, 1-14. Por poner un ejemplo, para S. Jerónimo el Espíritu Santo es arra para nuestra salvación, diferenciándola del signo (cf. ComEphI, 594).

55 San Agustín, el más citado por Cornelio a Lapide en todos sus comentarios.

56 Cf. TÁвet, M., Le trattazioni theologiche sulla Bibbia. Un approccio alla storia dell'esegesi. San Paolo, Milano 2003, 21-25. Además la obra de SimonetTi, M., Lettera elo allegoria. Un contributo alla storia dell'esegesi patristica. S. E. A. 23 (1985).

57 Hay cierta elasticidad a la hora de identificar a los Padres. En la nota $n^{\circ} 17$, hablamos en el sentido estricto de la palabra Padre (cf. O’Donnell, C. - Pié-Ninot, S., Diccionario de Eclesiología. «Padre de la Iglesia». San Pablo, Madrid 2001, 813-814). 
INSTAURAR TODO EN CRISTO.- En griego $\alpha^{\prime} \nu \alpha \kappa \varepsilon \phi \alpha \lambda \alpha \imath \omega \sigma \alpha \sigma \theta \alpha \mathrm{l}$, esto es recapitular, como lee S. Jerónimo, como si dijese: Dios propuso que todos los hombres y los ángeles, ya que eran totalmente distintos entre sí, aún más eran enemigos, propuso unir y volver a llamar y reunir en una sola cabeza, Cristo; en efecto pues dio a Cristo como cabeza de la Iglesia, como dice el v. 22.Y a partir del cap. 2, v. 19, expone: «Por consiguiente en este momento no sois huéspedes y extranjeros, sino que sois ciudadanos de los santos y familia de Dios», como si dijese: Cristo nos volvió a llamar para la sociedad de los ángeles, para que con ellos seamos hermanos, y ciudadanos celestes en la misma casa de Dios, es decir la Iglesia, bajo la misma guía y cabeza, que es el mismo Cristo. Este es el sentido genuino. Así Crisóstomo, Teofilacto, Anselmo, aún más también S. Agustín. [...].

En segundo lugar, dice Jerónimo ö $\alpha \alpha \kappa \varepsilon \phi \alpha \lambda \alpha i \omega \sigma \imath v$, que los oradores llaman la recapitulación cuando en el epílogo, aquello que ha sido dicho durante todo el discurso, de una forma dispersa es repetido de una forma resumida, e igualmente se llama a la memoria del juez. [...] ello con más excelente razón y abreviado tenemos el compendio en Cristo. Así Jerónimo, Crisóstomo y Teofilacto, esta palabra consumada y abreviada en la justicia. Aquí el sentido es sublime y responde bien tanto al griego " $\alpha \nu \alpha \kappa \varepsilon \phi \alpha \lambda \alpha \imath \omega \sigma \alpha \sigma \theta \alpha \mathrm{l}$, como al espíritu, al sentido y al amor del divino Pablo a Cristo.

En tercer lugar, Ireneo, en el libr. III, cap. VIII, enseña que todo en Cristo debe ser recapitulado, porque en la naturaleza humana se contienen todas las cosas y las especies de todas las cosas y grados como en la totalidad. De donde se dice que el hombre es un microcosmos, y consecuentemente como la Palabra divina asumió la naturaleza humana, entonces como todas las cosas en totalidad unió convertidas para sí; y para sí como autor y origen primero, del Verbo es decir, en el cual son creadas, volvió a llamar, y de este modo por su encarnación Cristo llevó a la gran dignidad a todas las cosas, y a todos casi las deificó. Aquí el sentido es simbólico. El primero es principalmente literal; en efecto Pablo trata de la restauración de los hombres caídos y de la Iglesia ${ }^{58}$.

Y todo este examen tan minucioso es para desmembrar las ideas y luego expresarlas de la forma más breve posible, es decir, en tres palabras que sean lo más literal posible a los Padres. Sin embargo, muchas veces su intención de ser breve y concisa a la hora de exponer las líneas interpretativas de los Padres en un sentido literal no ha sido de este modo ni breve ni uniforme en el método. Como podemos comprobar el objetivo se cumple en algunas cartas (o partes de ellas) de San Pablo en las que es suficientemente clara su exposición; sin embargo en otras donde el mismo Pablo es más elevado y confuso no se cumple dicho objetivo, como hemos podido evidenciar en la carta a los Efesios 1, 1-14 ${ }^{59} \mathrm{con}$ el tema de la «predestinación»y en Rom 8, $16^{60}$ cuando Cornelio a Lapide comenta

58 Cf. ComEphI, 591-592.

59 Podemos comprobarlo en el ejemplo anterior, como en todo el comentario a Ef 1, 1-14. Cf. ComEphI, 586-589.

60 Cf. ComRomVIII, 134-136. 
«Este espíritu da testimonio» para dejar bien claro que este testimonio de que somos hijos de Dios no es cierto con certeza de fe. Su exposición no es breve sino al contrario densa, siendo el versículo de los comentarios de Rom 8, 13-23 de más densidad.

Podríamos comprender que esto pueda suceder porque Cornelio a Lapide está desarrollando unos temas importantes como «la certeza de la fe» ${ }^{61}$ (la fe fiducial, la certeza de la que hablan los protestantes) que ha sido condenado por el Concilio de Trento frente a la doctrina de los protestantes (DH 1564).Y en efecto, es un tema justificado por el Concilio y no por la exégesis, por lo que necesita su espacio para aclararlo, recurriendo a los Padres (ya que es un tema que aparece en sus reflexiones). Hoy es un tema que pertenece a la Dogmática y, ya entonces, Cornelio lo introduce en sus comentarios $^{62}$.

A Lapide asume la exégesis de los Padres de la Iglesia tanto de los Santos Padres como la exégesis medieval (los cuatro sentidos de la Escritura). Asume la antigua exégesis pero con matices de cambio, de esta forma la nueva exégesis que realiza tiene toda la herencia anterior pero se le ve novedosa, porque la enriquece con la aportación del humanismo crítico, en orden a lograr una exégesis literal de carácter científico. Por ejemplo el fundamento de su exégesis es el texto griego, cosa que no ocurre en Santo Tomás (porque desconocía el griego). Además somete esta interpretación literal a la autoridad de la Iglesia, con lo cual pone freno a las desviaciones doctrinales. Y desde este marco general del sentido literal ortodoxo introduce el comentario el sentido alegórico, tropológico o anagógico ${ }^{63}$.

Cornelio desde la afirmación de que el Espíritu Santo es el autor de las Escrituras reconoce sólo dos sentidos (en los cuales se encuentran los demás sentidos por motivo de contenido y materia) en las Escrituras: el literal y el espiritual. Este último sentido es rechazado primero por Lutero, posteriormente por otros protestantes y por último, los racionalistas. Para nuestro autor el sentido espiritual o místico no puede deducirse sino a partir de las palabras del sentido literal cuando ofrece una figura o algún tipo.Y viceversa, todas aquellas palabras que son tomadas en sentido literal que ofrecen alguna figura o tipo puede tener debajo de ellas también un sentido espiritual ${ }^{64}$. El ejemplo lo tenemos en el comentario de Cornelio a los Gálatas 4, 2455. Si comparamos estos dos sentidos

61 Analizaremos estos temas dogmáticos en el siguiente apartado.

62 Cf. ComRomVIII, 134.

63 Cf. Andrés martínez, M., Historia de la Teología Española, 119-121.

${ }^{64}$ Cf. Lubac H, DE., Exégèse médiévale. Les quatre sens de l'écriture. Aubier 1959. En esta obra De Lubac menciona a nuestro autor, en su apartado sobre los sentidos donados por el Espíritu Santo, haciendo referencia a la disertación De sensu spiritali, dans CORN. A LAPIDE, Opera, 21 (1875), I et XIII.

65 Cf. ComGálIV, 555: «QUAE SUNT PeR Allegoriam Dicta.- Allegoria Rhetoribus est continua metaphora, estque in verbis et vocibus: hic vero, et passim apud Ecclesiasticos scriptores, significant typum et figuram, quam non voces, sed res et gesta in veteri Testamento significabant res et sacramenta novi Testamenti. Unde subdit: 
entre sí tenemos que afirmar que ambos son inspirados; el literal es universal y el típico o espiritual es restringido a casos concretos. El literal es el fundamento del espiritual o típico. Así también lo manifiesta el exegeta del S. XIX Cornely al alabar los comentarios de Cornelio a Lapide a toda la Sagradas Escrituras dice que no siempre transmite suficientemente con solicitud el sentido literal, pero expone doctamente el sentido espiritual y algunos de sus comentarios son óptimos sin ninguna duda para exponerlos ${ }^{66}$.

Otro dato digno de subrayar es que Cornelio asume de los Padres el consenso de la tradición católica sobre los textos bíblicos. Nuestro autor, por una parte, quiere exponer y presentar la interpretación tradicional de la Iglesia en todas sus variantes como un gran tesoro y riqueza para el lector; y por otra parte, desarmar a los protestantes ante la crítica que dirigían a la exégesis católica de forzar las Escrituras. Fijémonos en la siguiente exposición:

23. Pero también nosotros mismos que tenemos las primicias Del espíritu, GemiMOS DENTRO DE NOSOTROS, ESPERANDO LA ADOPCiÓN DE LOS HiJOS DE Dios.

fijate en aquello (tò): teniendo las primicias del espíritu.

En primer lugar, San Agustín (en Quaestiones 83 y 67) explica así, como si dijera: Nosotros, los cristianos, que nos ofrecemos a Dios como primicias.

En segundo lugar, mejor lo explican San Ambrosio y Anselmo, como si dijera: Nosotros, los Apóstoles, que recibimos los primeros y mejores frutos del Espíritu y os parecemos admirables, gemimos, sin embargo, bajo este peso del cuerpo.

En tercer lugar, de forma optima San Juan Crisóstomo, Teodoreto y Cirilo (Thesaur. Lib. 14, c. 1), dicen: Todos los cristianos (principalmente los de aquella Iglesia primitiva) con justicia reciben las primicias del Espíritu, a saber, el verdadero conocimiento de Dios, el amor y esperanza de la verdadera felicidad, y esto, a menudo, con la abundancia de la divina consolación; pues esta gracia y la vida piadosa y cristiana son primicias de la redención y de la liberación del pecado, a la cual se sobreañade la gracia consumada, es decir la gracia de la felicidad y de la gloria y la perfecta redención y liberación de todo mal, que será realizada en la resurrección. Ésta, en efecto, será la redención de nuestro cuerpo de toda muerte y miseria, la cual anhelamos y por la cual gemimos. Ya que Pablo no habla aquí sólo de los Apóstoles, como es evidente por los vv. 15 y 24 , sino de todos los cristianos ${ }^{67}$.

HAEC ENIM (graece $\alpha$ $\tau \alpha$ l, ipsae, Sara videlicet et Agar) sunT (id est per allegoriam, significant) DuO TESTAMENTA,- novum scilicet et vetus. Ita Hieronymus, Chrysostomus, Theodoretus, Anselmus. Vide Can. 6, ubi dixi hoc loco quatuor esse Scripturae sensus. Primus, litteralis, est planus litterae sensus, scilicet Abraham ex Agar genuisse Ismaelem nauraliter, Isaacum ex Sara supernaturaliter. Secundus, allegoricus, cum ait: «Quae sunt per allegoriam dicta; haec enim sunt duo testamenta». Tertius, tropologicus, cum ait, vers. 29: «Sed quodmodo tunc is qui secundum carnem natus fuerat, persequebatur eum qui secundum spiritum: ita et nunc». Quartus, anagogicus, cum ait, vers. 26: «Illa autem quae sursum est Jerusalem, libera est, quae est mater nostra».

66 Cf. Cornely, R., Introct. In S. Script. Libros Compendium. Editio Nova. Auctore A. Merk. Sumptibus P. Lethieleux, Editoris. Parisiis (VI e) 1927, 284.

67 Cf. ComRomVIII, 139. 
Vemos como en este comentario Rom 8, 23, Cornelio a Lapide hace uso de los Padres para iluminar su comentario y nos hace descubrir ante nuestros ojos la complementariedad que existe entre ellos; aunque no se contradicen entre ellos, unos Padres son más explícitos que otros. Aún existiendo un cierto consenso entre ellos, a la hora de interpretar el texto bíblico, Cornelio a Lapide acepta este «consensum Patrum» pero él lo que realiza es más bien una clasificación y distinción entre los mismos Padres.

Cornelio a Lapide nos ofrece implícitamente con su método exegético -con la tradición, expresada en el consentimiento de los Santos Padres y teólogos- una especial eficacia para determinar el sentido auténtico de las Sagradas Escrituras, como pide el Concilio de Trento. Como es obvio, que a partir de estos presupuestos, Cornelio a Lapide en sus comentarios recurre a otros comentarios tanto patrístico como a autores escolásticos, lo que supone un apoyo y autoridad para exponer una posición teológica (sirven para fundamentar una idea bíblica, justificar interpretaciones de Concilio, demostrar el acuerdo entre la propia posición con aquella de la Iglesia antigua y universal, etc). Por ello, muchas veces pueden parecernos que en los comentarios de nuestro autor aparezcan verdaderas catenae de opiniones o glosas ${ }^{68}$. La Glosa ordinaria fue un recurso muy utilizado por los grandes de la teología como Pedro Lombardo y Santo Tomás. Nuestro autor citará en sus comentarios a la Glosa ordinaria ${ }^{69}$ y a un gran glosador griego como es Photius ${ }^{70}$, patriarca cismático de Constantinopla en el S. IX, como aparece en el comentario a la carta a los Efesios:

Fíjate en tercer lugar: Por acquisitionis en griego es $\pi \varepsilon p ı \pi 0 \imath \eta \sigma \varepsilon \omega \varsigma$, porque algunos traducen acción de defender, de reivindicación del hombre libre; mejor nuestro autor, Teofilacto, Pothius, que no Vatablus, Budeus, Erasmo, acquisitionis; $\pi \varepsilon p \iota \pi 01 \varepsilon^{\ulcorner} \imath \theta \alpha \imath$ en efecto no sólo reivindicar, sino también significa preparar, enriquecerse, así todos del griego entienden. Luego acquisitio se dice adquirir en propiedad, la sustancia, los bienes; es decir, el pueblo cristiano, al cual Cristo adquirió para sí y para Dios con tantos trabajos, dolores, lágrimas, aún más con la sangre y la muerte ${ }^{71}$.

68 Voz «CAdenas EXEGÉticas» (Cf. Enciclopedia de la biblia. T. II. Ed. Garriga, S. A. Barcelona 1963, 1620): «Colección de extractos o escolios de autores, presentados como exégesis del texto bíblico. El comentario a la Biblia se hizo con mucha frecuencia a base de citas de los antiguos Padres. El nombre cadena, de origen relativamente moderno, expresa la concatenación de textos. Entre los latinos se ha indicado con este nombre de Catena Aurea de Santo Tomás a los evangelios, pero su realidad es más antigua».

Voz «GlosA» (Cf. Enciclopedia de la Biblia, 910-912): «Las colecciones exégeticas con trozos de comentarios patrísticos abocaron entre los latinos al género de obras llamadas "glosas", verdaderos centones del quehacer interpretativo de la antigüedad eclesiástica. En la alta Edad Media empezaron los glosadores, cuyo trabajo parcial quedó después recogido en la obra de Anselmo de Laón $(+1117)$ y de su escuela llamada Glossa interlinearis -breves anotaciones aclaratorias colocadas entre las líneas del texto bíblico- y la "glosa ordinaria" -comentario seguido al texto sagrado- que gozaron de una gran estima entre teólogos y comentaristas medievales».

69 Cf. ComGálIV, 556.

70 Voz «Glose» (Cf. Dictionnaire de la Bible. Tomo III. Letouzey et Ané, Editeurs. Paris 1903, 255)

71 Cf. ComEphI, 594. 
El resultado de lo visto hasta ahora es que nuestro autor acoge la Patrología ${ }^{72}$ como un elemento integrante más de su exégesis. Además nuestro autor asume de forma firme -siendo fiel al Concilio de Trento en su sesión IV- de no ir en contra de la interpretación unánime del consenso de los Padres, a la hora de hacer la interpretación del texto sagrado (DH 1507).

Un dato nuevo a resaltar en la exégesis de Cornelio a Lapide es la referencia a los Concilios ecuménicos: en concreto al Concilio de Trento. Y decimos que es una novedad al formar parte de la exégesis de Cornelio porque hace una lectura desde él, con el sentir de la Iglesia, en cierto modo se hace referencia a la doctrina eclesial, al Magisterio de la Iglesia ${ }^{73}$. El Concilio de Trento presta un servicio importante al método teológico cuando subrayó que la primera fuente de cualquier verdad de la salvación es el Evangelio o la Buena Nueva anunciada primero por Cristo, de viva voz, y luego transmitida por los apóstoles. Este mensaje de Cristo existe ahora para la posterioridad en una doble comunicación en los libros escritos y en las tradiciones no escritas (DH 1501). En cierto modo la ciencia de la fe, al menos en su función positiva, tiene que remontarse a esta última fuente: la Escritura y la tradición.

\subsection{A la luz de los Doctores (los teólogos y exegetas modernos)}

Una nueva luz entra a formar parte de la exégesis de Cornelio a Lapide: los teólogos y exegetas modernos. Novedad porque también es nuevo el tiempo que le toca vivir a nuestro autor (S. XVI-XVII), unos siglos de una extraordinaria importancia para la Iglesia general y para la teología en particular. Para la Iglesia porque con la Reforma protestante se rompe la unidad de la cristiandad occidental; para la teología, porque esta época de controversia es para ella un periodo de renacimiento, en el que se abandona las sutilezas abstractas -en las que estaba

72 Cf. Hamman, A., Patrología-Patristica, DPAC II (1988) 1711-1715. «Patrología»: Este término tiende a expresar sobre todo el estudio histórico y literario (vida y obras) de los escritores antiguos. Los antiguos no trazaron una frontera rígida entre la antigüedad cristiana y la Edad Media; dieron fácilmente el nombre de "Padres" a los escritores posteriores, como en el caso de las antiguas Bibliothecae Patrum, que van hasta el S. XV-XVI. «Patrología»: En su origen era un adjetivo, sobrentendiendo a la teología. Aparece el término en el S. XVII entre los teólogos luteranos y católicos, que distinguían la teología en bíblica, patrística, escolástica, simbólica, especulativa».

73 Cf. Wicks, J., Introducción al método teológico. Ed. Verbo Divino, Estella (Navarra) 2001, 104: «Un segundo paso de importancia a largo plazo fue la declaración de Trento relativa a la interpretación eclesial normativa de la Biblia. En este punto, Trento expresa la conciencia que tiene la Iglesia de poseer el significado del mensaje bíblico y de ser poseída por él. Especifica que esta comprensión es una parte continua y constante del ser mismo de la Iglesia. El texto menciona a los Padres de la Iglesia y con ello recuerda los argumentos de Juan Fisher a favor de una "tradición herméutica" patrística y conciliar. El decreto especifica que "toca a la Iglesia juzgar el verdadero significado e interpretación de la Sagrada Escritura". En la época de Trento, el término "Magisterio" no estaba en uso, pero la realidad está presente allí donde Trento se apropia de lo que los controversistas católicos habían propuesto acerca de la existencia de un "juez de controversias" en la Iglesia». 
anclada desde el S. XV- y se vuelve más positiva, más humanista y más abierta a los nuevos problemas de la Edad Moderna. No es que los teólogos renuncien a la especulación y a la sistematización teológica, sino que se fundamentan en el estudio crítico de las fuentes y la orientan a iluminar las circunstancias vitales de su época. Una de las cuestiones de actualidad, en aquel momento, es el tema de la justificación a raíz de la nueva doctrina de Lutero y de aquellos que le siguen. Este va ser un punto esencial de la controversia entre católicos y protestantes ${ }^{74}$.

Pues bien, en contra de la justicia forense o imputada que proponían los protestantes el Concilio de Trento enseñó el carácter interior de la justificación (cf. la sesión VI) como un hecho que modifica realmente al hombre justificado. De esta forma el Concilio tridentino se vincula a la teología medieval que presenta varias tesis sobre la gracia, describiéndola como un habitus, una real modificación accidental de la estructura natural del hombre (la gracia como justificación). Por otra parte, los protestantes agitan un problema que el Concilio de Trento redujo a los términos correctos de la revelación, pero sin llegar a resolverlos. Por lo que nos encontramos con el problema de la consistencia del hombre en el plan de Dios, el problema de la autonomía y del significado de la libertad frente a la primacía absoluta de la iniciativa salvífica de Dios. Toda esta problemática dieron origen a las controversias postridentinas (controversias de auxiliis, bayana y jansenistas). Y todas estas controversias se relacionan con otro momento de la tradición, es decir, con el momento patrístico-agustiniano, en el que se veía a la gracia sobre todo como auditórium gratuito, concedido por Dios a la libertad pecaminosa, impotente e incapaz de merecer el hombre. Estas controversias impulsan un análisis más completo de la tradición patrística, tanto latina como griega ${ }^{75}$.

Este es el contexto teológico donde nuestro autor se va a mover, apareciendo en sus comentarios diversas discusiones teológicas (dogmáticas) con otros teólogos: el problema de la gracia creada, la gratuidad de lo sobrenatural y la colaboración de la libertad con la gracia.

Una pregunta importante teológica que surge en el tema de la filiación adoptiva en Cornelio a Lapide ¿qué es el espíritu de adopción, los dones del Espíritu Santo o es el mismo Espíritu Santo? Aunque parece claro en Cornelio, por muchas partes de sus comentarios, que es el mismo Espíritu Santo; en otras puede parecer que es la gracia de la filiación fruto del Espíritu Santo. Nuestro autor nos presenta un tema teológico clave de su época, la gracia creada y la gracia increada:

EsPíritu de PROMISIÓN.- como si dijese, estáis sellados no con un signo corporal, es decir, la circuncisión, como el ganado, dice S. Crisóstomo, así como son sellados los judíos; sino como los cristianos, e hijos racionales, estáis sellados «con

74 Cf. Andrés, M., La teología española en el S. XVI, T. 2, BAC Madrid 1977, 335-343.

75 Cf. PArera, B., «La escuela tomista española en el S. XVII», en Historia de la teología española. Tomo II, Madrid 1987, 9-20. 
el espíritu de la promesa», esto es «con la promesa» la cual, o sea Dios prometió por medio de los profetas, como Ezequiel 36, 26: «Os daré un corazón nuevo y un espíritu nuevo», para Joel 2, 28 y otros. Este espíritu prometido por Dios es la caridad, la justicia, la paz y el gozo de conciencia, que es recibida en el bautismo, después de haber creído; luego cada uno estáis puestos a prueba y manifestáis que en la conversión de costumbres, y en la santidad e inocencia de la vida cristiana. Algunos así lo entendieron, «estáis sellados por este espíritu», esto es lo dones del Espíritu Santo ${ }^{76}$.

Nos adentramos en el desarrollo de este apartado, en palabras de Cornelio a Lapide, con una lectura de la justificación desde la filiación adoptiva (como noción que puede ser aglutinante de toda su teología sobre la gracia), en uno de los textos bíblicos que hemos trabajado:

Además el Espíritu Santo nos adopta como hijos para sí de dos formas: primero, por medio de la gracia, en cierto modo accidentalmente; segundo, por medio de la naturaleza, en cierto modo substancialmente. Pues en la justificación se comunica al hombre la misma substancia y naturaleza de Dios y, de modo admirable, se une a él mismo. Así lo enseña Francisco Suárez en el libr. XII del De Deo trino et uno, cap.V. Acerca de esto ya dije mucho en Oseas 1, 10 y diré más adelante en 2 Pe 1, 4, según aquello: «Para que seamos hechos partícipes de la naturaleza divina» ${ }^{77}$.

Es evidente que los temas teológicos de su época van a influir en nuestro autor propiciando que se reflejen en el fondo de su exégesis -su conocimiento amplio y sólido de los tratados de Teología y las cuestiones controvertidas de su tiempo-y, no solamente los usa sino que juega (por decirlo de alguna forma) con ellos constantemente en los lugares paralelos, entra en la discusión científica con otros teólogos. Así con la doctrina escolástica sobre la gracia creada por la cual se da la transformación interna del hombre justificado a través de una cualidad interna e inherente a él. Por lo tanto, la gracia creada aparece como el fundamento exclusivo de la inhabitación y unión del hombre con Dios ${ }^{78}$. Cornelio a Lapide en la definición anterior del ejemplo expuesto expresa la gracia increada (el Espíritu Santo) como momento previo a la gracia creada y nos habla de nuestra adopción mediante una causalidad formal. E introduce, junto al tema de la justificación unido a la adopción filial, el tema teológico de la inhabitación trinitaria (la unión de Dios en y con el hombre justificado, desde dos perspectivas: la apropiación de las tres personas divinas y presencia personal del Espíritu Santo), y el tema de la gracia (la gracia santificante y la causa formal de la justificación).

Cf. ComEphI, 594.

Cf. ComRom VIII, 134.

78 Cf. LADARIA, L. F., Teología del pecado original y de la gracia. Antropología teológica especial. BAC Madrid $1997^{2}, 166-170$. 
Un primer lugar paralelo, de Rom 8, 15 donde expone su reflexión es en Oseas 1, 10, como podemos ver:

Que la justicia inherente o la gracia justificante, por la que somos santificados y adoptamos como hijos de Dios, no sea una simple cualidad, como propiamente se imaginan, sino que comprende muchas cosas, es decir, la remisión de los pecados, la fe, la esperanza, la caridad, y otros dones, y el mismo Espíritu Santo como artífice de todo don (y por consiguiente toda la Santísima Trinidad). En efecto, todo esto es recibido por el hombre en la justificación ${ }^{79}$.

En un segundo momento, dentro del comentario a Oseas, dirige toda esta voluminosa reflexión contra aquellos que piensan que en la justificación y en la adopción filial el Espíritu Santo se da en sus dones y no en misma substancia y persona. Sin embargo no aparecen los nombres de aquellos teólogos, quienes son atacados por Cornelio. Pero sí aquellos que comparten su propia opinión: de esta tradición, menciona primero a San Buenaventura, después a Pedro Lombardo (Maestro de la Sentencias), a Duns Scoto, a Santo Tomás de Aquino, además se menciona de la escuela de Santo Tomás a Vázquez y Gregorio de Valencia. Para terminar destacando a Francisco de Suárez y su obra De Deo trino et uno, libro 12, cap. V, núm. 8, 11, 12. Con Suárez escribe él: El Espíritu Santo llega de un nuevo modo según su substancia comenzando a estar presente en el alma del justo. La pregunta que nos surge es la siguiente: ¿Quiere Cornelio a Lapide seguir la reflexión teológica en la misma línea argumentativa que estos teólogos para su reflexión sobre la filiación adoptiva del cristiano? ¿Sobre qué puntos se apoya nuestro autor?

Desde San Buenaventura a Santo Tomás de Aquino resalta que ellos consideran la gracia creada está relacionada con la gracia increada y que está ultima es fundamental en la justificación; dirá Santo Tomás que gratia gratum faciens disponit animam ad habendam divinam personam (Cf. I. q. 43 a. 3 ad 2).Y de Francisco Suárez sobre el razonamiento de la presencia de Dios en el hombre dirá que la amistad entre Dios y los hombres por la gracia supone y hace necesario la presencia del amigo, del Espíritu Santo en el alma. El problema que se nos ofrece es si la gracia creada es previa o posterior a la gracia increada. Sería interesante ver esta discusión entre Francisco Suárez y Cornelio a Lapide, cada uno desde unas categorías diferentes e inseparables entre amistad y filiación adoptiva. Y en qué sentido la inhabitación del Espíritu Santo es causa formal precisamente de la filiación divina del justificado.

Un segundo lugar paralelo, de Rom 8, 15, es 2 Pedro 1, 4, donde Cornelio a Lapide vuelve a repetir lo dicho en Oseas 1, 10. Aquí de nuevo, en dos notas, se acentúan de forma reiterada la real, personal y substancial presencia de Dios ${ }^{80}$.

\footnotetext{
79 Cf. ComOsI, 298.

80 Cf. ComEphI, 411-412.
} 
Lo que sí aparece en el comentario a 2 Pe 1, 4: «Que por estas cosas os hagáis partícipes de la naturaleza divina», que no aparecía en Oseas 1, 10 son algunos que llegaron a errar sobre este versículo, en referencia a los protestantes y los iluminados:

En primer lugar, Osiander pensó que nos unimos a la divinidad, de tal modo que somos justificados realmente por la mismísima justicia y santidad de Dios, porque otros herejes viendo que es imposible, dijeron que hemos sido justificados por el mérito y la justicia de Cristo que se nos imputa a nosotros. Ved Belarmino lib II De Justif. Cap.V.

En segundo lugar, Miguel Servet, al que Calvino procuró condenar a muerte y al fuego como hereje en Ginebra, pensó las mismas cosas de la divinidad trasladadas a los justos; así como el alma trasladada al cuerpo mientras que la anima y vivifica, de lo cual Beza dijo esto: son ridículos los que imaginan aquí una transfusión de la esencia divina a nosotros, que el impío Servet obstinadamente defendió interrumpidamente hasta la muerte; y sin embargo son muchos los que piensan que una gran injuria, la gran injusticia hecha a un hombre bueno.

En tercer lugar, en exceso algunos contemplativos en el tiempo de Gerson, y aún más en el nuestro, han imaginado que por medio de la contemplación ellos se unen a Dios, de tal forma que la misma naturaleza de estos se sumerge en el deísmo profundo de la divinidad, aniquilando a la humana, y toda se transforme en divinidad; lo cual fue un error de Almaricus, del cual fua acusado falsamente Ruisbrochius por Gerson, que expone desde la epístola de aquel a Batolomé Carthusie, la cual escribe contra la defensa hecha de Ruisbrochius por Juan de Schonhovia. Así algunos partidarios de Eútiques (monofisismo del S.IV) decían que la humanidad de Cristo había sido consumida por la divinidad, así como se consume el mercurio cuando se mezcla con el oro; así que en Cristo hubiese una sola naturaleza, es decir, divina, no dos. Por eso Apolinar pensó que Cristo no hubo mente humana sino tan sólo divina. Y los monoteístas pensaron que Cristo sólo tenía una voluntad, a saber la divina. Omitiendo estos delirios y sueños de estos fanáticos, S. Ambrosio en Epist. 38 y Ecumenio, piensan que aquí nosotros somos hechos partícipes de la naturaleza divina por medio de Cristo; pues en Cristo nuestra naturaleza humana es hecha consorte de la divina porque está unida a ésta de forma más estrecha en la misma hipóstasis delVerbo ${ }^{81}$.

De este texto debemos resaltar dos elementos, que consideramos interesantes. Primero, que Cornelio está haciendo todo un alegato de Apología contra los protestantes. Segundo, la discusión teológica de Cornelio a Lapide con los protestantes o reformadores, tanto en esta exposición como en otras muchas veces en sus comentarios. Creemos que nuestro autor pone de manifiesto su conocimiento personal sobre el pensamiento de los teólogos protestantes y los utiliza en sus propios comentarios para refutarlos desde dentro de su propio pensamiento, dejando en evidencia su falta de fundamentos (como diría un dicho español: si no puedes con tu enemigo únete a él).

81 Cf. ComEphI, 410. 
Además en el comentario a Rom 8, 16 Cornelio cuando habla sobre la certeza de fe-ahora lo vemos desde el punto de vista de los teólogos y exegetas modernos (ya antes lo hemos visto desde los Padres) - menciona junto al Concilio de Trento a Catarino, Cayetano, Andrés Vega, Ruardo y Pereira, como sigue a continuación:

Advierte que este testimonio del Espíritu Santo, por el cual se nos da testimonio de que somos hijos de Dios, no es cierto con certeza de fe, como pretenden los herejes. Esto lo condena el Concilio de Trento, así como el Apóstol en 1 Cor 4, 3 y en otros lugares; ni siquiera es cierto con certeza infalible, como sostienen Catarino y Cayetano; sino que es cierto con una certeza meramente conjetural; certeza que aumenta con la santidad. Hasta el punto que Andrés Vega, Ruardo, y siguiendo a éstos, también Pereira ${ }^{82}$.

Constatamos que A Lapide une la certeza del testimonio de ser hijos de Dios con la certeza de fe de los reformadores.

¿Pero cómo hemos de entender la certeza de la gracia de ser hijos de Dios?

El Concilio de Trento responde a la cuestión de la certeza de la gracia en relación con la doctrina de los reformadores acerca de la fe fiducial. Para los reformadores significa el abandono total del hombre, que se reconocer pecador, en manos de Dios, que promete ser misericordioso con él, por los méritos de Cristo. La fe por lo tanto no es una disposición sino una condición necesaria para que se realice la mutación por la que Cristo asume nuestros pecados y nos imputa su justicia. Sin embargo el Concilio de Trento (DH 1533-1534) en el cap. 9 excluye la necesidad e incluso la posibilidad de la certeza absoluta acerca de la propia justificación, defendida por los protestantes. Las controversias sobre el grado de certeza que se puede tener respecto al propio estado de gracia entre los teólogos nacen de las divergencias en la concepción de la naturaleza de la «certeza» auténtica y del modo como la conclusión teológica participa de la certeza de la fe ${ }^{83}$.

Por lo tanto no debemos confundir entre la certeza de fe con la cual el hombre acoge y cree lo revelado por Dios como cierto y la certeza de ser hijos de Dios (nuestra experiencia personal), de ello solo tenemos una certeza conjetural.

Otro elemento de consideración es que nuestro autor no sólo recoge en su obra a los grandes teólogos de la época, sino también a los grandes exegetas que le precedieron y que tanta repercusión tuvieron antes y después del Concilio de Trento. Cornelio a Lapide retoma el esfuerzo del movimiento exegético de los jesuitas españoles de algunos libros de la Biblia del S. XVI, de la envergadura de Juan Maldonado (1534-1583), Alfonso Salmerón (1515-1585), Francisco Toledo (1532-1596), Francisco Rivera (1514-1591), Benito Pereira (1535-1610), todos ellos hacen un gran esfuerzo teológico en el alba del Concilio de Trento y dará su fruto en el S. XVII, dentro de una óptica de controversia confesional, se podría decir que antes la Escritura

82 Cf. ComRomVIII, 134.

83 Cf. Flick, M. - Alszeghy, Z., El evangelio de la gracia. Ed. Sígueme, Salamanca 1965, 706-715. 
servía para alimentar los debates, ahora los comentarios se han convertido en un instrumento de combate. La unidad del saber teológico es manifiesta y la interpretación de la Escritura es objeto de debate en los grandes controversias sobre la gracia ${ }^{84}$. Nuestro autor al realizar su comentario a toda la Biblia va a significar un referente para todos nosotros de cómo es leída la Biblia después de la Reforma Católica.

Para finalizar, lo que si hemos constatado por parte de Cornelio es su silencio en sus comentarios (en concreto, en 2 Pe 1,4) de una referencia a Leonardo Lessio (+1623) y a Dionisio Petavio (+1632) teólogos contemporáneos de nuestro autor, que de una forma parecida plantean semejantes respuestas al tema de cómo el hombre puede ser divinizado por medio sólo de la gracia creada. Para ellos, el hombre es justificado en cuanto que recibe el don de la gracia creada e increada; y en virtud de estos dones, se perdonan los pecados al hombre, se hace amigo de Dios, templo de la Santísima Trinidad, hijo adoptivo de Dios y partícipe de la naturaleza divina. Ambos teólogos distinguen los efectos de la gracia creada y la gracia increada ${ }^{85}$. Aunque Cornelio a Lapide comprende la gracia santificante como la gracia creada y la gracia increada ${ }^{86}$.

\section{CORNELIO A LAPIDE Y EL MÉTODO TEOLÓGICO}

Finalmente, según lo que hemos podido constatar anteriormente en el desarrollo del método exegético de Cornelio a Lapide podríamos hacer una segunda lectura, con otras palabras, como un subtítulo: el método positivo. Después de que nuestro autor ha fijado en primer término el sentido literal (asumiendo la exégesis de los Padres), usando la filología y la critica textual; y posteriormente, ha enriquecido su exégesis con la riqueza teológica de los Padres y Doctores de la Iglesia y el Concilio de Trento, podremos decir que nuestro Cornelio a Lapide también ha realizado y nos revela una gran labor teológica en su exégesis. Él mismo se reconocía, en la carta dedicatoria de su obra Comentario a las cartas apostólicas, como teólogo:

Por esto yo no busco los adornos vacíos, ni cortejo la elegancia. En efecto, hago de Teólogo, no orador; busco la verdad, busco la utilidad, no la sombra y la pompa; insisto en las cosas, no en las palabras; principalmente ya que el mismo Apóstol, al cual interpreto, se declara a sí mismo ignorante con el estilo, no así con la ciencia ${ }^{87}$.

$Y$ añade:

¿En efecto, qué cosa buscamos? La gloria de Cristo, no la nuestra, para que el nombre de Cristo se propague por todas partes del orbe por nosotros y por todos, según la medida de la gracia dada a cada uno por $\operatorname{Dios}^{88}$.

84 Cf. Bedovelle, G., - Roussel, B., Le temps des Reformes et le Biblie. Ed. Beauchesne, Paris 1989, 361-368.

85 Cf. Flick, M. - Alszeghy, Z., El evangelio de la gracia, 598-600.

86 Cf. Com2PetriI, 412-413.

87 Cf. A lapide, C., Carta dedicatoria, 11.

88 Cf. A lapide, C., Carta dedicatoria, 12. 
Por lo tanto, podemos decir que nuestro autor a la vez que ha desarrollado el método escolástico, desde el espíritu humanista y con el espíritu del Concilio de Trento, ha realizado un equilibrio entre exégesis bíblica, la patrología y la dogmática. Ofreciéndonos un estudio realmente positivo, directo e inmediato de los manantiales del saber bíblico y una obra teológica rigurosamente científica.

En Romanos 8, 15 -punto central de nuestra tesis- Cornelio a Lapide definía el espíritu de adopción como la caridad y la gracia del Espíritu Santo, o mejor aún, el mismo Espíritu Santo, por el cual fuimos adoptados como hijos de Dios.

En definitiva nuestro autor pone la causa de nuestra adopción en la esencia de la inhabitación del Espíritu Santo (y de toda la Santísima Trinidad), o sea en el Don increado.

La pregunta siguiente es qué relación existe entre el Don increado y los demás dones creados, infusos en la justificación, principalmente con la gracia santificante en la que todos radican. Esta pregunta nos lleva a tres problemas que podríamos plantearnos: ¿Puede darse estado de gracia sin inhabitación divina? ¿Puede darse, por el contrario, inhabitación divina sin los dones creados? ¿Qué elemento es primero en la justificación, la inhabitación o los dones creados?

Veremos ahora como nuestro autor realiza su propia investigación científica para verificar si es la gracia la causa de que Dios venga a nosotros o es más bien, la comunicación de Dios para habitar en nosotros, y en cuanto tal la causa de la gracia, para la filiación adoptiva del cristiano. Donde mejor lo podemos comprobar es en los textos de Oseas 1, 10 y 2 Pe 1, 4, donde el autor nos remite para comprobar las razones de su tesis. Nosotros nos vamos a dedicar a Oseas 1, 10 porque en 2 Pe 1, 4 se repite casi en su totalidad lo dicho en Oseas. Centremos nuestra atención en las fuentes teológicas que el propio Cornelio a Lapide ha utilizado:

\subsection{La base bíblica, tesis probada desde la Escritura}

En Oseas 1, 10 nos describe Cornelio su tesis:

Dios da al alma no sólo la gracia, la caridad y los otros dones del Espíritu Santo, sino también el mismo Espíritu Santo, que es el primer don, que Dios regala al hombre. Dios en la justificación nos hubiera podido hacer justos y santos solo por la gracia y la caridad [...]. Pero la inmensa bondad de Dios no contento con este beneficio, quería darse a sí mismo a nosotros y así mismo santificarnos y adoptarnos. Por esto se ha unido el Espíritu Santo desde su propia iniciativa con sus dones de la gracia y la caridad, ya que él mismo personal y substancialmente se vierte a las almas, al mismo tiempo, que ellos ${ }^{89}$.

89 Cf. ComOsI, 297. 
Y cita las palabras del Apóstol en Rom 5, 5: «el amor de Dios ha sido derramado en nuestros corazones por el Espíritu Santo que nos ha sido dado», además, el Espíritu Santo que personalmente desciende sobre las almas, trae con él las otras personas divinas, el Padre y el Hijo, de las cuales él no se puede separar. Así viene toda la Trinidad, personal y substancialmente al alma justificada y adoptada, y permanece en ella como en un templo, según las palabras de 1 Jn 4, 16: «Y nosotros hemos conocido y creído en el amor que Dios nos tiene. Dios es amor, y el que permanece en el amor permanece en Dios, y Dios en él», y según 1 Cor 6, 17: «En cambio, él que se une al Señor se hace un solo espíritu con él». Por eso ha dicho Cristo antes de su muerte en su divina oración al Padre, en Jn 17, 21: «Te pido que todos sean uno. Padre, lo mismo que tú estás en mí y yo en ti, que también ellos estén unidos a nosotros; de este modo, el mundo podrá creer que tú me has enviado». Porque el Espíritu Santo en el que todos participan y que en todos está, uno y el mismo es. Todos somos en un mismo Espíritu Santo uno, como las tres personas divinas son una en la naturaleza divina.

Cornelio a Lapide, desde la exégesis de este texto, nos ofrece una síntesis de los datos de la Escritura sobre la comunicación de Dios al hombre. También él mismo ha realizado la exégesis a dos textos que pueden corroborar lo dicho o ponerlo en duda:

\section{a) Una afirmación}

Ef 1, 13: «Y vosotros también, los que acogisteis la palabra de la verdad, que es la buena noticia que os salva, al creer en Cristo, habéis sido sellados por él con el Espíritu Santo prometido».

Cornelio a Lapide en su comentario a Efesios 1, 13 prueba que El Espíritu Santo es bueno y santo, no por participación de otro, sino por ser fiel a su propia naturaleza, y que en consecuencia es Dios; Él es el arquetipo de la bondad y la santidad, para que él que es marcado por el Espíritu Santo, asuma la forma e imagen de su santidad.

De donde se puede deducir que la justificación es una sigilación divina que Dios hace imprimiendo en nosotros el sello, el Espíritu Santo, que nos es dado y que nos infunde las virtudes y la gracia. Es lo que posiblemente los destinatarios de la carta habían experimentado de Cristo, es designado aquí como una sigilación del Espíritu Santo. Cornelio reúne en el mismo comentario la idea de sello y la idea de arras, y asegura que el Espíritu Santo en cuanto unido a nosotros es la causa del valor sobrenatural de nuestras personas y prenda para obtener la gloria, que es el complemento del estado de gracia ${ }^{90}$.

90 Cf. ComEphI, 594. 
b) Un problema

San Pablo en Gál 4, 5-6 parece favorecer la concepción posteriorista de la inhabitación: la supremacía de la Gracia sobre la Ley mosaica, dice que si bien todos los santificados en ambas economías eran hijos de Dios; pero los del Antiguo Testamento eran como herederos párvulos, todavía sujetos al tutor, por lo cual no se diferenciaban de los esclavos, a pesar de ser verdaderos herederos de Dios; más los de la Nueva Ley son hijos mayores independizados del tutor y herederos en acción. Y añade el Apóstol: «Y puesto que sois hijos, Dios os ha enviado el Espíritu de su Hijo a vuestros corazones, que clama "Abba, Padre"». Según la apariencia de la letra, la razón de la misión del Espíritu Santo a nuestros corazones es que somos hijos de Dios, y que ya estamos en gracia.

La solución de Cornelio a Lapide es que el Apóstol no habla simplemente de la misión, sino de la misión del Espíritu Santo que nos hace llamar a Dios, Padre $^{91}$.

\subsection{Los Padres, tesis probada desde la Tradición}

Cornelio también se basa en los Padres como S. Cirilo y S. Atanasio, y en conexión con ellos el exegeta Cardenal Toledo, nos dice nuestro autor: En efecto, en la justificación y en la adopción como filiación adoptiva es introducido en el alma la gracia y la caridad, y con ellas el mismo Espíritu Santo, la gran divinidad y santidad de la Santísima Trinidad, para que podamos participar de su misma naturaleza y de sus dones según nuestra condición, unidos a su santidad ${ }^{92}$.

Por lo tanto, los Padres al hablar de la santificación del hombre con el Espíritu Santo para ser justificados, para la filiación adoptiva, con toda claridad manifiestan que la gracia y los dones creados son el efecto resultante de la comunicación sobre nosotros, en virtud del cual quedamos divinizados y semejantes a Dios. Cornelio a Lapide se basa en una homilía de San Basilio (Padre capadocio) De Spiritu Sancto, en la que éste denomina a aquellos en los que vive el Espíritu Santo, Santos. Y argumenta la divinización de los hijos de Dios por el efecto del Espíritu Santo.Y une a estas palabras el tema de la causa formal de la adopción. La adopción es una, pero virtualmente es doble: la causa formal de la primera aceptación como hijos de Dios por la gracia, es la gracia misma y la causa formal de la segunda adopción, que acontece por la participación del Espíritu Santo, es el mismo Espíritu Santo. Añade Cornelio que el medio es la gracia, para que el Espíritu Santo viva en el alma del justificado ${ }^{93}$.

Con ello Cornelio se ajusta a la filosofía de Aristóteles, ya que la forma no se introduce en el sujeto antes de que éste tenga la disposición conveniente. Por

\footnotetext{
Cf. Com GalIV, 551

Cf. ComOsI, 297.

Cf. ComOsI, 598.
} 
tanto, el Espíritu Santo inhabitante (con inhabitación propia) no existe, hasta que exista la gracia dispositiva en el hombre ${ }^{94}$.

En los documentos doctrinales de la Iglesia, el Concilio de Trento, sólo se limita en la recensión de las causas de la justificación a repetir el conocido texto de San Pablo a los Efesios 1, 13: «la causa eficiente, Dios misericordioso, que gratuitamente lava y santifica, sellando y ungiendo "con el Espíritu Santo de su promesa, que es prenda de nuestra herencia"». Además, en referencia al Concilio, Cornelio dice que la justicia inherente o la gracia santificante, por la cual somos santificados y adoptados como hijos de Dios, no es una simple cualidad, como algunos se imaginan, sino que comprende muchas cosas, es decir, la remisión de los pecados, la fe, la esperanza, la caridad, y los otros dones, y el mismo Espíritu Santo, autor de los dones (y consecuentemente toda la Santísima Trinidad). Todo esto es infundido en los hombres en la justificación, como enseña el Concilio de Trento en la sesión sexta, capítulo $7^{95}$. De donde podríamos deducir que la justificación es una sigilación divina que Dios hace imprimiendo en nosotros el sello, el Espíritu Santo, que nos es dado y que nos infunde las virtudes y la gracia (DH 1529-1530).

\subsection{Los teólogos, tesis probada desde los Doctores de la Iglesia}

La primitiva escolástica heredó también la Tradición de los Padres, así aparecen citadas por Cornelio las dos grandes escuelas, Santo Tomás y San Buenaventura, que defienden que la fe nos enseña que el don Increado, Dios inhabitante, está en los justos como principio efectivo de la regeneración y vivificación. El Espíritu Santo es el nombre propio del don, porque él mismo se dona a todos los justos.

La referencia más cercana y que Cornelio a Lapide señala con más insistencia es Francisco Suárez y su obra De Deo trino et uno, lib. XII, cap. V, num. 8, 11, 12; unida a la declaración de que el Espíritu Santo nos adopta para sí de dos formas: primero, por medio de la gracia y segundo, por medio de su naturaleza. Y explicita más, diciendo que en la justificación se comunica al hombre la misma substancia y naturaleza de Dios y, de modo admirable, se une a él mismo (Cf. ComRomVIII, 134). De Suárez toma que el Espíritu Santo llega a estar presente en el alma de los justos de un modo nuevo según su substancia, que antes no tenía. Cita a favor de esta sentencia a San Agustín, San Ambrosio y San León. La razón de ello lo toma las palabras de Suárez sobre su razonamiento sobre la presencia personal y real de Dios en el hombre: la amistad entre Dios y los hombres por la gracia supone la presencia del amigo, del Espíritu Santo en el alma ${ }^{96}$.

94 Cf. ARISTÓTELES, Física, Libro II. 3. Las causas. Biblioteca Clásica Gredos. Madrid 1995, 140-146.

95 Cf. ComOsI, 298.

96 Cf. ComOsI, 298. 
Nos aparece un problema: si la conclusión de Cornelio a Lapide es que la amistad exige moralmente la inhabitación. Si nuestro autor apuesta por la prioridad de la inhabitación del Espíritu antes que la gracia, y antes que la amistad, quedaría anulada su propia propuesta.

La cuestión tiene en sí poca importancia para la práctica de la vida cristiana, pero en el orden especulativo tiene el valor de complementar un sistema; pues la solución de ella depende si ha de renunciar o no al argumento deducido de la amistad para probar la presencia sustancial del Espíritu Santo inhabitante. Nos queda ésta pregunta en el aire.

Para concluir este punto del trabajo debemos decir que Cornelio a Lapide nos ha mostrado su propio método exegético-teológico, que bien podría verse reflejado dentro de las claves que Melchor Cano (+1560) recoge en su obra De locis theologicis, todo un tratado metodológico de la teología moderna. Este tratado ofrece al teólogo un instrumento criteriológico y metódico no sólo para sistematizar las verdades teológicas, sino más bien para poderlas fundamentar. Melchor Cano con su obra no pretende definir los loci según la materia teológica, sino al contrario obtener la verdades teológicas desde loci. Estos lugares teológicos donde el teólogo podrá encontrar los argumentos teológicos y sus pruebas sean de índole negativa o positiva, son los siguientes: La Sagrada Escritura, la tradición oral, la Iglesia católica, los concilios, la Iglesia romana, los Padres, los teólogos escolásticos, la razón natural, la autoridad de los filósofos, la historia. De entre todos ellos la Sagrada Escritura y la tradición oral son exclusivamente los constitutivos de la fe, los siguientes a excepción de la razón natural, los filósofos y la historia, son los lugares teológicos en particular, siempre en vistas al método probatorio que hay que seguir en ellos. Y añade Melchor Cano que el buen teólogo no sólo debe fijar los principios teológicos sino también valorar su grado de certeza, para que en la colección del material el juicio teológico forme la conclusión ${ }^{97}$.

De esta forma Cornelio a Lapide basa su tesis, deducida de la doctrina bíblico-patrística, confirmada con los testimonios de los Padres y resuelta por los Teólogos que han afrontado esta cuestión.

\section{VALORACIÓN}

Ahora es el momento de valorar no sólo los criterios, sino también la ejecución de estos criterios. Porque una cosa es el método reflejo que el propio autor ha indicado: interpretar el sentido literal, en base a las tres lenguas clásicas (hebreo, griego y siríaco) y según la luz de los Padres y Doctores, y otra cosa es el método practicado.

97 Cf. Beumer, J., El método teológico. En Historia de los Dogmas. Tomo I, cuaderno 6. BAC, Madrid 1977, 99-102. también Cf. Wicks, J., Introducción al método teológico. Verbo Divino, Estella (Navarra) 2001, 18-24. 
Por tanto, tendremos que observar en qué medida nuestro Cornelio a Lapide se atiene a su propio método de trabajo o si realmente su exégesis toma otro rumbo distinto. Tendremos que fijarnos entre los diferentes criterios, que peso tiene cada uno de ellos dentro del método: ¿Son los Padres más importantes que la filología, o menos? ¿Hace una diferenciación entre la opinión de un Padre, de muchos Padres o existe un verdadero «consensus Patrum»? ¿Tienen los Doctores más peso, mayor importancia, que los Padres? ¿Qué influjo tiene el espíritu humanista en el autor? ¿Hay otros elementos que no se encuentran reflejados en su método?, etc.

Para Cornelio lo más importante era la solidez, brevedad, el método y la claridad máxima del sentido literal de las cartas. Hagamos una valoración y demos respuesta a estos interrogantes planteados:

1. Podríamos decir que los criterios que nuestro autor se marca le sirven como un marco de referencia. Cornelio no transmite claramente del todo el sentido literal del texto sagrado, donde además expone doctamente el sentido espiritual. Y en consecuencia con su idea directriz de ser metódico al seguir el sentido literal de toda su obra exegética, vemos que se esfuerza en dar unidad a su método personal.

2. Sin embargo, en cuanto a la brevedad, no siempre ha sido así, por lo que hemos de decir que Cornelio a Lapide añade grandes explicaciones a su sentido literal. Quedando un poco oscurecido este objetivo que Cornelio se marcó. Así también lo recoge el P. Romualdo Galdos, sobre este mismo tema en su comentario a la obra de Cornelio a Lapide, en el Tercer Centenario de su muerte y dice:

Si verdaderamente la explicación del sentido literal se extrae en las ediciones de Cornelio siempre de las letras mayores, y por el contrario, si todos los demás sentidos se expresan en los caracteres menores, entonces aparece claramente por todas partes la brevedad prometida por el autor; así a cada sentido, incluso en la forma externa y en la misma que se llama presentación tipográfica, se le da un momento propio: pues al sentido literal se le da primero, máxima y principal, a los restantes sin embargo el más secundario..$^{98}$

3. Con respecto a los criterios de realizar sus comentarios a la luz de los Padres, los textos originales de la Biblia y los Doctores modernos hemos de decir que estas tres fuentes del conocimiento o instrumentos del método de la teología positiva tiene una unidad en sí misma.

+ En referencia a los Padres, que son tantos los que él mismo cita, es difícil coordinar tantas opiniones (a veces cercanas, complementarias o diversas), nos parece que le plantearían un gran problema a nuestro autor. Así también lo expresa Romualdo Galdos:

98 Cf. GaLdos, R., De scripturisticis meritis P. Cornelii a Lapide, VD 17 (1937) 93. 
Pero más que el computo material, hay que resaltar el increíble trabajo intelectual, que cada página de la obra supone: el estudio del sagrado texto original y sus principales versiones; lectura y examen, asimilación de lo que hasta su tiempo se escribió alrededor del libro que comentar; formulación del propio juicio sobre cada texto y cada versículo bíblico; explicación de este mismo juicio con amplia y variada erudición sagrada o profana. Es fácil argumentar cuál cúmulo de trabajo importará tal método de composición, sobre todo si se considera que esta fatiga, comprendido el trabajo mismo del material a escribir, pesaba sobre un sólo hombre...99.

Sin embargo, Cornelio no se limita a elegir aquel Padre más cercano que pueda compartir su interpretación, con lo cual justificaría su intención. Sino, por el contrario, expone los diversos Padres (de forma literal y concisa), mostrándonos la complementariedad que entre ellos existe, y como uno mejor que otros son más explícitos y más óptimos a la hora de expresar el sentido del texto. Ante tal método de composición (lectura, examen, asimilación, juicio y explicación de la obra de tantos autores) de su obra se podría pensar que debajo su obra se encuentra oculta la glosa ordinaria (comentario seguido al texto sagrado) que gozaron de gran estima entre los teólogos y comentaristas medievales, pero que nosotros no podemos afirmar con rotundidad.

Lo que si podemos decir es que muestra de alguna forma un cierto «consenso de los Padres» delante de los ojos del lector, como doctrina común de la Iglesia y un rico tesoro de la patrística y de la exégesis escolástica. Decimos un «cierto consenso» porque a nuestro parecer Cornelio a Lapide hace más una clasificación entre las distintas interpretaciones de los Padres para terminar remarcando el sentido más pleno, que la unanimidad de interpretación. No podemos dudar que nuestro autor asume el consenso de los Padres, otra cosa es que entre los Padres exista un consenso tan explícito.

+ El Renacimiento y el humanismo traen consigo una revaloración de la antigüedad clásica y cristiana, en el plano de los textos y de la historia, y se afirma un verdadero retorno a las fuentes. En este mismo espíritu humanista, Cornelio a Lapide, introduce la Patrología en la exégesis invocando a los Padres en las controversias que oponen a la Reforma y a la Iglesia católica. Y de este modo nos ofrece también un rico material patrístico. Cornelio a Lapide asume la herencia de la vieja exégesis tanto patrística como medieval (los cuatro sentidos de la Escritura) pero le da un aire nuevo desde la filología. Pensamos que no queda muy claro en el método de Cornelio a Lapide la conexión existente entre filología y los Padres, es decir entre la filología y la teología tradicional de los Padres: ¿Qué fuente de las dos tiene mayor autoridad en el comentario, en el caso que ambas se contradigan?

En la búsqueda de Cornelio del sentido literal de su obra, él va usar la filología de su época. Él no se conforma sólo con el texto griego y latino, sino que

99 Cf. Galdos, R., Nel terzo centenario della morte di Cornelio a Lapide, CivCatt 88 (1937) 211. 
va más allá consultando para sus comentarios otras versiones: hebraico, siríaco y del arameo. El retornar a las fuentes y el conocimiento de las lenguas antiguas, le lleva al estudio, la penetración y sutileza de juicio necesario para confrontar entre ellos los textos griegos, hebreo, latino, siríaco, arameo. Para él no existe problema a la hora de utilizar tanto los textos sagrados inspirados con los no inspirados. Creemos que con la firme intención de probar la autenticidad de la versión oficial -la Vulgata- frente a los protestantes y de dar luz desde las versiones no inspiradas a los textos inspirados, en aquellos lugares que es oscuro. Sin embargo, nuestro autor, no abusa de la filología sino que solo la utiliza cuando el versículo puede parecer oscuro, buscando encontrar claridad en el término. Lo que si queda puesto de manifiesto es que el texto griego es el fundamento de su exégesis y no tanto el latín de la Vulgata. Pero queda sin expresar en su método tanto la relación del uso de la Vulgata y las demás versiones como la relevancia del texto griego en su exégesis.

+ Otro elemento esencial y de importancia son los teólogos modernos y los exegetas del S. XVI y XVII, que son citados en sus comentarios. Cornelio a Lapide no sólo vuelve a las fuentes, sino que también confronta su pensamiento y lo pone en discusión con otros teólogos. Intenta iluminar los problemas de su momento, desde la Escritura, desde los Padres, desde la doctrina de la Iglesia y desde las reflexiones de la teología de su época para dar una respuesta a ellos. Así aparecen temas dogmáticos vistos desde la exégesis bíblica, iluminados desde diversas perspectivas como hemos visto a lo largo de nuestro trabajo, la filiación adoptiva, la justificación, la gracia, la certeza de fe, o la inhabitación del Espíritu Santo, etc.

Hemos de destacar de su discusión teológica -por lo que concierne a nuestro trabajo- a S. Buenaventura, a Santo Tomás de Aquino y a Francisco de Suárez. Este último va a ser el punto de referencia de dialogo para su reflexión teológica sobre la inhabitación del Espíritu Santo para la filiación adoptiva del cristiano. Desde estas reflexiones con dichos teólogos entra en contacto con el método medieval; sin embargo en la exposición de su nuevo método no la encontramos. Su método teológico, en nuestra opinión, es más teología positiva que teología especulativa.Y lo creemos por el hecho de que como dijimos al principio del disertación puede explicarse por la suma de circunstancias como son la situación histórica, que venía dada por la oposición a la degenerada escolástica, a esto le sumamos el humanismo y la Reforma, que reclaman un recurso a la autoridad y, por consiguiente, una preferencia por la teología positiva.

Cornelio a Lapide confronta su obra tanto con los exegetas católicos como los heterodoxos (sin omitir su discusión con ellos). Con los católicos va a compartir las mismas preocupaciones por el esfuerzo de dar el lugar que se merece la ciencia exegética, el estudio y meditación de la Sagrada Escritura con el sentir de la Iglesia frente a los reformadores del S. XVI que intentan apartar el valor normativo de la tradición de la Iglesia, para quedarse con la «Sola Escritura». 
Podemos concluir valorando positivamente la capacidad y la talla intelectual de nuestro autor en los comentarios a las cartas, porque lo realiza desde el estudio escolástico (propio de su formación intelectual), desde el espíritu humanista (hombre de la cultura de su tiempo) y desde el espíritu del Concilio de Trento (hombre de fe y de gran amor a la Iglesia). Cornelio hace un verdadero equilibrio entre la exégesis bíblica, la Patrología y la dogmática. Nos encontramos ante un trabajo serio y bien hecho, un estudio positivo, directo e inmediato a las fuentes del saber bíblico; y ante todo una obra rigurosamente científica ${ }^{100}$.

Para terminar hay que decir, que Cornelio a Lapide se adelanta a lo que será la exégesis del S. XX, siempre guardando las distancias, al exponer auténticamente las íntimas y esenciales relaciones entre la Biblia, la Tradición y el Magisterio eclesiástico (Concilio Vaticano II, DV 8, 9, 10). Cornelio a Lapide nos abre el camino para considerar que la Sagrada Escritura es el alma de la Teología, como lo ha querido enseñar el Vaticano II, y como lo fue antes entre los Padres, entre los grandes teólogos, como San Agustín y Santo Tomas. Y que ella puede ofrecer un gran servicio a la Teología.

100 Cf. Becker, K. J., El método Teológico, Revista Española de Teología 61 (2001) 173-184. 
